\title{
Report of the Working Group
} on Treatment of Under 18 year olds Presenting to Treatment Services with Serious Drug Problems 


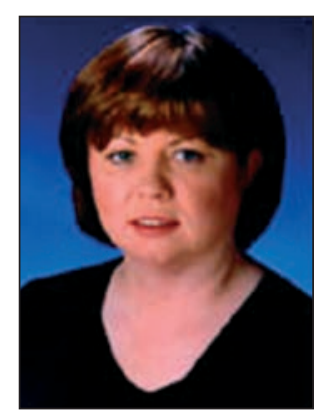

\section{Foreword by Tánaiste and Minister for Health and Children}

I am pleased to publish the Report of the Working Group on the treatment of under 18 year olds presenting to treatment services with serious drug problems.

Action 49 of the National Drugs Strategy 2001-2008 identifies the need for the development of a protocol for treating under 18 year olds presenting with serious drug problems. Given the seriousness and complexity of the issues involved, this Report represents a major step towards addressing the needs of these vulnerable young people.

Drug misuse is an affliction of our society and recognising and intervening at an early stage of an individual's drug misuse is extremely important. This Report sets out ways of achieving this.

The Report emphasises the need for a multi-disciplinary approach and also underlines the need for a service design which encourages and retains young people in treatment and rehabilitation services. With this in mind the Working Group recommends a four tiered model of service delivery which provides a realistic, flexible and adaptable framework.

Finally, I would like to record my thanks and appreciation for the work of the members of the Working Group in producing this comprehensive, informative and useful Report.

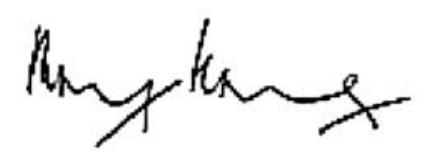

Mary Harney T.D.

Tánaiste and Minister for Health and Children 



\section{CONTENTS}




\section{EXECUTIVE SUMMARY}

\section{Background}

Action 49 of the National Drugs Strategy is as follows:

"To develop a protocol, where appropriate, for the treatment of under 18 year olds presenting with serious drug problems especially in light of the legal and other dilemmas which are posed for professionals involved in the area. In this context a Working Group should be established to develop the protocol. The Group should also look at issues such as availability of appropriate residential and day treatment programmes, education and training rehabilitative measures and harm reduction responses for young people. The Group should report by mid 2002."

A number of other Actions within the Strategy are directly relevant to Action 49: in particular Action 59 calls for easy access to counselling services for young people seeking assistance with drug-related problems and Action 60 calls for treatment services for young people to include family involvement and community integration phases.

\section{Approach}

The former Eastern Regional Health Authority (ERHA) established a Group chaired by the Department of Health and Children and comprising a broad range of statutory and non-statutory service providers and community representatives in October 2001. To fulfil its remit, the Group undertook a number of initiatives, including:

- an examination of the legal issues surrounding treatment

- a review of available literature

- a review of relevant data

- a review of services within the former ERHA, now the Health Service Executive (HSE) and of service gaps nationally

- focus groups of service users within and outside the former ERHA, now the HSE Eastern Regional Area and

- a review of the treatment issues raised by the above.

The issues raised under Action 49 of the strategy proved to be more complex than anticipated. As a result it was not possible to meet the mid-2002 deadline. Furthermore, the Group was reluctant to adopt a simplistic approach to those issues. In particular, it felt that the complexity of individual needs in this client group 
implied that a protocol format could be overly restrictive and that it was preferable to try to establish appropriate broad guidelines or models for treatment.

\section{Summary of Conclusions}

The Group's conclusions can be grouped into four broad categories: patterns of serious drug misuse amongst children and their implications, legal and ethical issues, model for service delivery, and access to services.

\subsection{Drug Misuse Patterns}

Within the HSE Eastern Regional Area first treatment contacts by under 18 year olds have varied substantially since treatment data began to be collected on a systematic basis, reaching a high point of 386 first treatment contacts in 1996 before falling to 108 in 2000. Over the decade, there were 2,034 new cases involving clients under 18 years old. Over the period the proportion of females increased, the proportion living with family fell, and a small but significant number were homeless or living alone with young children. Throughout the period over one third of clients reported that they had left school early.

The main problem drugs reported by new cases within the HSE Eastern Regional Area were opiates, cannabis and to a lesser extent volatile inhalants and ecstasy. Over one fifth of new cases reported ever having injected an illicit substance. The reported median age of first use of the problem drug fell from 15 to 14 years of age between 1995 and 2000, while the median age of first injecting an illicit substance was 16 for most of the period.

Outside the HSE Eastern Regional Area first treatment contacts by under 18s rose from 111 in 1996 to 213 in 2000. Over the period there were 629 new cases involving clients under 18 years old. As in the HSE Eastern Regional Area, the proportion of females increased; the majority lived with family although a significant proportion were living alone with young children and a large proportion had left school early. The main problem drugs reported were cannabis and to a lesser extent ecstasy and volatile inhalants.

It is clear that attendances by children account for a very substantial proportion of the workload of the addiction services. 


\section{EXECUTIVE SUMMARY}

The Group felt that services needed to be child-centred. In particular, they should be designed in such a way that young people would be encouraged into and retained in order to benefit from treatment and rehabilitation services.

The Group felt that services needed to be adaptable and flexible given the fluctuations which have been experienced over time in numbers presenting for treatment and the variation in the drug-related and other problems which are presented.

The Group felt that prevention and early intervention initiatives should focus primarily on developing and supporting protective factors, for example in relation to those at risk of early school leaving and that the prevention and early intervention initiatives set out in the National Drugs Strategy should be accelerated.

\subsection{Legal and Ethical Issues}

The Group acknowledged the difficulties for statutory, voluntary and community personnel working in this area, particularly in relation to the issue of consent.

In this regard the Group noted that family involvement in the treatment of a child or adolescent drug misuser lead to better outcomes for the child or adolescent. As such the first priority for treatment services was to try to secure the involvement of the client's family. However, it was accepted that it was not always possible to secure family involvement or indeed parental consent.

The Group noted that the legislation in place allowed persons aged 16 and 17 to consent on their own behalf to certain treatments. However, there appeared to be some doubts as to whether the Courts would accept that such consent could apply to drug treatment. In this context it was felt that the UK concept of "Gillick competence", whereby professionals could assess whether or not a young person was competent to give informed consent on their own behalf, could play an important role.

The Group noted that particular issues arose in relation to a small number of young persons where it was felt that secure residential facilities would be appropriate in terms of their short term health needs.

In view of the complexity of the issues involved, the Group felt that substitution treatment for under 18 year olds should not be initiated outside a specialist context. 


\subsection{Treatment Model}

The Group agreed that treatment services for child and adolescent problem drug misusers should be based on the tiered approach identified in the literature review by Dr. Gemma Cox. In an Irish context, the four tiers may be interpreted as follows:

\section{Tier 1}

Services which have contact with young people but which do not have specialist expertise in either adolescent mental health or addiction, such as teachers, social services, members of An Garda Síochána, GPs, community and family groups.

\section{Tier 2}

Services which have specialist expertise in either adolescent mental health or addiction, but not both, such as Juvenile Liaison Officers (JLO), Local Drugs Task Forces (LDTFs), home school liaison, Youthreach and drug treatment centres.

\section{Tier 3}

Services which have specialist expertise in both adolescent mental health and addiction, i.e. multi-disciplinary teams comprising people with a speciality in adolescent addiction.

\section{Tier 4}

Services which have specialist expertise in both adolescent mental health and addiction, and the capacity to deliver brief but very intensive treatment, e.g. in-patient or day hospital.

Within this overall structure, close co-operation between the four tiers will be essential. For example, staff working at Tier 3 would be expected to work closely with and support interventions delivered by Tier 1 and 2 services and to support the interventions delivered at Tier 4. From the point of view of an individual client, it is clear that he/she will progress through different tiers, depending on the severity of his/her treatment needs.

In essence, this model of treatment delivery requires explicitly establishing the networks required to deliver targeted and appropriate services to children and adolescents presenting with problem drug misuse. Its success relies heavily on the effective sharing of information, pooling of resources and development of a concerted focus amongst the various statutory and non-statutory bodies which will interact with an individual child or adolescent. 


\section{EXECUTIVE SUMMARY}

The Group felt strongly that the services which existed on the ground tended to fall into Tiers 1, 2 or 4 and that the greatest need in terms of developing this model of service delivery was in Tier 3. The Group also noted that the development of Tier 3 services could appropriately evolve in different ways within and outside the HSE Eastern Regional Area.

\subsection{Access to Services}

The Group agreed that services should:

- strive to be adolescent specific, but didn't need to be addiction specific

- be local and accessible

- have multiple disciplines available on-site and

- be able to offer assessment, treatment and aftercare.

The Group noted that a wide range of services were available across the country. Nonetheless, there was a strong perception among under 18 year old drug misusers of a lack of access to services catering for and suitable to their needs both within and outside the HSE Eastern Regional Area.

In this context the Group felt that establishment of adolescent specific services within the HSE Eastern Regional Area needed to be progressed as a matter of urgency. The key factor in this regard was identified as the establishment of a properly resourced multidisciplinary team(s) capable of supporting existing services and of developing new services within existing physical structures, for example general adolescent services, health centres etc.

At the same time the Group was conscious of the need to address service access outside the HSE Eastern Regional Area, where the smaller numbers raise additional challenges as regards the availability of adolescent specific accessible addiction services. However, the Group was strongly of the view that the tiered model can be adapted to suit circumstances outside of the HSE Eastern Regional Area and pointed to the potential for Regional Drugs Task Forces to help create the treatment networks required.

\subsection{Resource Requirements}

It is clear that addressing the needs of under 18 year olds will require additional resources to be directed at this client group.

The resources required should be released through greater co-ordination of the 
efforts of the wide range of bodies involved in funding and delivering services in this area, e.g. HSE Areas, LDTFs, Partnerships, Probation and Welfare, Gardaí, Prison Services, Department of Education and Science, FÁS, community and voluntary sector treatment providers etc.

Achieving greater co-ordination and maximising the impact of existing resources also requires the support and leadership of Tier 3 services.

In this context Regional Drugs Task Forces can have a very significant role and specific consideration should be given to resourcing this role in the development and implementation of their strategic plans. In particular, the Group felt that funding should be made available to each Regional Drugs Task Force outside the HSE Eastern Regional Area to provide for the appointment of a person to examine the links and gaps in the existing service.

Within the HSE Eastern Regional Area, additional investment needs to be made for the development of Tier 3 services as a matter of urgency. 


\section{INTRODUCTION}

\section{CHAPTER ONE - INTRODUCTION}

\section{Background}

Ireland's National Drugs Strategy 2001 - 2008 provides a comprehensive approach to tackling the drugs problem in Ireland. Its overall strategic objective is to significantly reduce the harm caused to individuals and society by the misuse of drugs through a concerted focus on the four pillars of supply reduction, prevention, treatment and research. The Strategy identifies 100 individual actions across those four pillars and assigns responsibility for their implementation.

Action 49 of the National Drugs Strategy is as follows:

"To develop a protocol, where appropriate, for the treatment of under 18 year olds presenting with serious drug problems especially in light of the legal and other dilemmas which are posed for professionals involved in the area. In this context a Working Group should be established to develop the protocol. The Group should also look at issues such as availability of appropriate residential and day treatment programmes, education and training rehabilitative measures and harm reduction responses for young people. The Group should report by mid 2002."

This report has been produced in response to that requirement of the National Drugs Strategy. Its recommendations also serve to implement the young people's component of several other actions of the Strategy, in particular Action 59 which calls for easy access to counselling services for young people seeking assistance with drug-related problems and Action 60 which calls for treatment services for young people to include family involvement and community integration phases.

\section{Policy Context}

In considering the comprehensive approach outlined by the National Drugs Strategy it is important to be cognisant of other key strategic policy documents in relation to children and young people; the UN Convention on the Rights of the Child is in essence a bill of rights for all children. It contains rights relating to every aspect of children's lives including the right to survival, development, protection and participation. Ireland ratified the convention in 1992. The convention recognizes the critical role of the family in the life of the child stating that the family as the fundamental group of society and the natural environment for the well being and 
growth of all its members and particularly children, should be afforded the necessary protection and assistance so that it can fully assume its responsibilities in the community. The involvement, where appropriate, of extended family members should be taken into consideration in delivering local arrangements for individual children.

The National Children's Strategy: Our children, their lives, provides an integrated framework as well as a broader policy context for the delivery of services to children over a ten year period. The strategy reflects the aspirations and concerns of children themselves and those who care for them. This is demonstrated by the "whole child" approach which addresses all aspects of a child's life. The context within which services are developed is also characterized by increasing public awareness of the plight of children who are neglected, abused, homeless and/or who appear before the courts.

The Health Strategy: Quality and Fairness - a Health System for You emphasizes the need for greater co-ordination between child welfare and protection and primary care services. It emphasises that closing the gap between the advantaged and disadvantaged requires a level of planning that is based on clear evidence and ensures that funding is channelled to appropriate service developments.

\section{Legislative Framework}

The Child Care Act, 1991 places a legal obligation on the HSE to promote the welfare of children who are not receiving adequate care and protection.

The Children Act, 2001 provides for the reform of juvenile justice and for the replacement of the Children Act, 1908. It provides for the convening of Family Welfare Conferences, extends the Child Care Act, 1991 in relation to non offending children in need of special care and protection and establishes the Special Residential Services Board.

The Education (Welfare) Act, 2000 provides for the entitlement of each child to a certain minimum education, the registration of children receiving education in places other than recognised schools, the compulsory attendance of certain children at recognised schools and the establishment of the National Education and Welfare Board. 


\section{INTRODUCTION}

\section{Young People in the National Drugs Strategy}

It is clear that problem drug misuse is not confined to a particular age group. Nonetheless, young people are heavily represented amongst those presenting to treatment services with serious drug problems. Treatment data collected by the Health Research Board indicates that during the 1990s, one-fifth of those presenting to drug treatment services were under 18 years of age. This data implies that those attending treatment in Ireland were the youngest in Europe over that period.

Many of the National Drugs Strategy Actions are relevant to framing a response to the drugs problem which addresses the needs of children and adolescents who become involved, or are at risk of becoming involved, in drug misuse.

For example, Action 19 requests that early incidences of the use of alcohol or drugs by young people coming to Garda attention be followed up by community police and/or health and social services.

Actions 29 - 37 foresee a wide range of information and supports of direct relevance to young people and parents being delivered by the Department of Education and Science in partnership with the Health Promotion Unit of the Department of Health and Children. These include the development of the life skills essential to prevention through the Social, Personal and Health Education programmes, the development of schools drug policies and the development of corresponding actions within the non-school sector e.g. Voluntary Training Opportunities Scheme (VTOS), Youthreach and Community Training Workshops operated by FÁS.

In relation to services provided by or through the HSE, Actions 59 and 60, concerning access to counselling services and family involvement respectively, refer explicitly to young people. Of course, most service providers are faced with the need to specifically address the particular requirements of child and adolescent as well as adult clients. Accordingly, the broad range of Actions related to treatment and rehabilitation are relevant in this context.

\section{Approach}

The former Eastern Regional Health Authority (ERHA), now the Health Service Executive Eastern Regional Area, established a Group, chaired by the Department 
of Health and Children, comprising a broad range of statutory and non-statutory service providers and community representatives in October 2001, with a view to delivering on Action 49 of the National Drugs Strategy. The membership of the Group is listed in Appendix I.

The issues raised under Action 49 of the strategy proved to be more complex than anticipated. As a result it was not possible to meet the mid-2002 deadline. Furthermore, the Group was reluctant to adopt a simplistic approach to those issues. In particular, it felt that the complexity of individual needs in this client group implied that a protocol format could be overly restrictive and that it was preferable to try to establish appropriate broad guidelines or models for treatment.

The Group limited its work to young persons who have serious problems stemming from drug misuse. In relation to serious drug misuse the International Classification of Diseases definition of "a pattern of psychoactive substance use that is causing damage to health... either physical or mental" was used by the Group.

With a view to fulfilling its remit, the Group agreed upon an approach which was aimed at:

(i) reviewing the available data and literature in relation to the treatment of persons under 18 years of age presenting with serious drug misuse problems

(ii) taking into account the importance of education and prevention initiatives, as well as the role of rehabilitation and aftercare

(iii) considering the legal and ethical issues facing service providers involved in this area

(iv) identifying the current level of service provision for children and adolescents with serious drug problems

(v) including, to the greatest extent possible in the consideration of this issue, the experiences of service users and their families. 


\section{INTRODUCTION}

\section{Initiatives}

Consistent with this approach and with a view to discharging its remit, the Group undertook a number of initiatives as set out below.

\subsection{Literature Review}

The Group commissioned a literature review to support its work. The tender required that the review would provide an overview of the available literature in relation to the interventions which are utilised in medical, psychosocial, systematic family and community approaches to meet the needs of young people who have serious problems associated with substance misuse. The review was to be presented in such a form as would allow the Group to make recommendations on the specific areas highlighted in Action 49 of the National Drugs Strategy.

Following a tender process the Addiction Resource Centre was awarded the contract for the review. A paper was prepared by Dr Gemma Cox for consideration by the Group entitled Young People and Drugs A Review Document - Treatment of Under 18 Year Olds for Serious Substance Misuse. Much of the information on best practice presented in the paper was derived from two UK Reports, the 1996 Health Advisory Service (HAS) publication Children and Young People: Substance Misuse Services and the updated HAS (2001) Review The Substance of Young Needs.

\subsection{Review of Relevant Data}

The Group is obliged to Dr Hamish Sinclair and Dr Jean Long of the Drug Misuse Research Division of the Health Research Board for reviewing the available data on prevalence and nature of problematic drug use and providing much of the material in Chapter Two.

\subsection{Legal and Ethical Issues}

The Group conducted an examination of the legal and ethical issues surrounding treatment. In the context of some very complex legal issues concerning treatment and consent in the context of children and adolescents presenting with serious substance misuse problems, the Group received the assistance of Roger Greene and Sons Solicitors and others.

\subsection{Review of Services}

The Group undertook a review of services and service gaps nationally. This task was undertaken by a sub-group comprising Dr Derval Howley (HSE Eastern Regional Area), Mr Jim Doyle (HSE South Western Area), Ms Vivienne Fay (HSE 
East Coast Area) and Ms Antoinette Kinsella (HSE Northern Area).

Through the Area Operations Managers within the HSE Eastern Regional Area and the Regional Drugs Co-ordinators in the other HSE Areas, service providers throughout the country were consulted in relation to what they perceived to be the gaps in the present service provision to under 18 year olds and also in relation to their suggested future development of services.

The Group also undertook a mapping of service provision by HSE Areas and community and voluntary agencies for under 18 year olds presenting with serious drug problems within the HSE Eastern Regional Area. These services, which are summarised in Appendix II, reflect the considerable variety of services which are relevant to the needs of children and adolescents presenting with problem drug misuse.

\subsection{Service User Groups}

The Group identified the need to include the views of young people in its work. Accordingly, a Service Users Sub-Group was formed comprising Ms Alice O'Flynn (HSE Eastern Regional Area), Ms Celine Martin (Inchicore Community Drug Team), Mr Seamus Noone (Drug Treatment Centre Board), and Mr Bill Ebbitt (HSE Midland Area). Thus the Sub-Group comprised service providers within the youth, community and addiction services nationally and within the HSE Eastern Regional Area.

In order to map the views of young people a structured questionnaire was drafted and used as a basis for discussions with groups in different parts of the country. These consultations took particular account of the literature review which had been undertaken and particular attention was given to the tiered model of service provision recommended by the Health Advisory Service.

\subsection{Review of Treatment Issues}

The Group invited Dr Bobby Smyth, consultant in child and adolescent psychiatry with the HSE South Western Area to assist it in reviewing the treatment issues raised by its work. 


\section{INTRODUCTION}

\section{Structure of Report}

The Group's conclusions can be grouped into four broad categories: the context for serious drug problems amongst children, legal and ethical issues, model of service delivery and access to services.

Chapter 2 considers the context for serious drug problems amongst children and adolescents, particularly in view of the trend for very young attendees at drug treatment services. Notwithstanding changes in the age profile of problem drug misusers reflected in recent data published, the number of children and adolescents still presenting to drug treatment services points to considerable challenges in relation to education and prevention as well as treatment services.

Chapter 3 considers legal and ethical issues, particularly in relation to consent and in relation to the potential for uncertainty around capacity to consent for different interventions related to problem drug misuse.

Chapter 4 outlines the tiered model for service delivery favoured by the Group for providing services to the young people affected.

Chapter 5 reviews some priority issues around access to services which have been identified by service users and service providers during the course of the Group's work.

Chapter 6 summarises the Group's conclusions.

The Group wishes to acknowledge the assistance of all those who have participated in and assisted its deliberations. The Group takes full responsibility for its conclusions and recommendations. 


\section{CHAPTER TWO - CONTEXT}

\section{Background}

This chapter provides an overview of the extent of problem drug misuse amongst children and adolescents under 18 years of age, both in terms of misuse of drugs (prevalence) and treatment seeking for problem drug misuse. This is examined in the context of the main demographic trends.

\section{Demographic Trends}

Ireland has the largest proportion of the population under 18 years of age among the EU Member States (Table 1).

Table 1 Persons under 18 years as a percentage of total population in EU Member States as of the 1st January 2001.

\begin{tabular}{ll}
\hline Country & $\%$ \\
\hline Ireland & 26.5 \\
France & 22.7 \\
United Kingdom & 22.6 \\
Luxembourg & 22.3 \\
Netherlands & 22.1 \\
Finland & 21.9 \\
Sweden & 21.8 \\
Denmark & 21.7 \\
Belgium & 21.1 \\
Austria & 20.1 \\
Portugal & 19.9 \\
Greece* & 19.0 \\
Germany & 18.8 \\
Spain & 18.2 \\
Italy & 17.4 \\
\hline
\end{tabular}

*1st January 2000

Source: Eurostat

This high proportion is all the more striking given the fact that the number of people in Ireland under the age of 18 years has been steadily decreasing both in terms of 
absolute numbers and as a percentage of the total population (Table 2). Between the Census years 1991 and 2002 the percentage of the total population under 18 years dropped from approximately one-third to one-quarter. This trend was observed for both males and females.

Table 2 Number of people (total, males and females) under the age of 18 years expressed as a percentage of the total population in Ireland for the Census years 1991, 1996 and 2002.

\begin{tabular}{lccc}
\hline & 1991 & 1996 & 2002 \\
\hline Total under 18 years & $1,145,393$ & $1,071,972$ & $1,013,031$ \\
\% of total population & 32.5 & 29.6 & 25.9 \\
& & & \\
Males under 18 years & 587,655 & 550,389 & 519,483 \\
\% of total male population & 33.5 & 30.6 & 26.7 \\
& & & \\
Females under 18 years & 557,738 & 521,583 & 493,548 \\
\% of total female population & 31.5 & 28.6 & 25.0 \\
\hline
\end{tabular}

Source: Census of Population (Volume 2) for the years 1991, 1996 and 2002. Central Statistics Office.

\section{Trends in the Prevalence of Illicit Drug Use}

Information on illicit drug use among Irish children and adolescents (under 18 year olds) is available from two national prevalence surveys, the Health Behaviour in School-aged Children Survey and the European School Survey Project on Alcohol and Other Drugs. Results from both surveys are reported below.

\section{1 Health Behaviour in School-aged Children Survey}

The Health Behaviour in School-aged Children (HBSC) Survey is a World Health Organisation (European) collaborative study of school-going children aged 10-17 years. Two HBSC surveys have been carried out in Ireland, the first in 1998 and the second in 2002 (Kelleher et al 2003). In both school surveys information on cannabis use and glue or solvent use was asked thus allowing trends to be examined over time. For cannabis use among school-going children (10-17 years) there was a drop in both lifetime (ever used) and last year (used in last 12 months) prevalence for boys but an increase for girls. One of the interesting findings in this 
survey is that there was very little difference in the proportion of children reporting cannabis use across the various socio-economic groups (Table 3 ).

Table 3 Trends in lifetime and last year prevalence (\%) of cannabis use among school-going children (10-17 years) between 1998 and 2002.

\begin{tabular}{|c|c|c|c|c|}
\hline Cannabis use & $\begin{array}{c}\text { School boys } \\
1998\end{array}$ & $\begin{array}{c}\text { School boys } \\
2002\end{array}$ & $\begin{array}{c}\text { School girls } \\
1998\end{array}$ & $\begin{array}{c}\text { School girls } \\
2002\end{array}$ \\
\hline Lifetime prevalence & 16.2 & 14.2 & 8.6 & 11.7 \\
\hline Last year prevalence & 14.0 & 13.4 & 6.7 & 9.5 \\
\hline
\end{tabular}

Source: The National Health and Lifestyle Surveys

In terms of glue or solvent use there was an increase in lifetime prevalence between 1998 and 2002 for both boys and girls (Table 4). This increase may reflect a growing willingness to experiment with solvents.

Table 4 Trends in lifetime prevalence (\%) of glue or solvent use among school-going children (10-17 years) in 1998 and 2002.

\begin{tabular}{lcccc}
\hline Glue or solvent use* & $\begin{array}{c}\text { School boys } \\
1998\end{array}$ & $\begin{array}{c}\text { School boys } \\
2002\end{array}$ & $\begin{array}{c}\text { School girls } \\
1998\end{array}$ & $\begin{array}{c}\text { School girls } \\
2002\end{array}$ \\
\hline Lifetime prevalence & 6.7 & 7.7 & 3.7 & 4.9 \\
\hline
\end{tabular}

* Last year prevalence of glue or solvent use was not reported

Source: The National Health and Lifestyle Surveys

\subsection{European School Survey Project on Alcohol and Other Drugs}

The European School Survey Project on Alcohol and Other Drugs (ESPAD) is a European wide collaborative study of school-going children aged 15 to 16 years. Two ESPAD surveys have been carried out in Ireland, the first in 1995 and the second in 1999. Again trends in drug prevalence can be examined. For cannabis, crack (excluding cocaine), ecstasy and LSD prevalence of use dropped between 1995 and 1999 for both school boys and girls (Table 5). The observed decreases were larger for boys than girls. For amphetamines, cocaine (excluding crack) and heroin, prevalence rates remained stable or increased slightly over the same time period. 
Table 5 Trends in lifetime prevalence (\%) of different illicit drug use among school-going children (15-16 years) between 1995 and 1999.

\begin{tabular}{|c|c|c|c|c|}
\hline Lifetime prevalence & $\begin{array}{c}\text { School boys } \\
1995\end{array}$ & $\begin{array}{c}\text { School boys } \\
1999\end{array}$ & $\begin{array}{c}\text { School girls } \\
1995\end{array}$ & $\begin{array}{c}\text { School girls } \\
1999\end{array}$ \\
\hline Amphetamines & 4 & 4 & 2 & 2 \\
\hline Cannabis & 42 & 35 & 31 & 29 \\
\hline Cocaine & 2 & 3 & 1 & 2 \\
\hline Crack & 4 & 2 & 2 & 1 \\
\hline Ecstasy & 11 & 6 & 6 & 4 \\
\hline Heroin & 3 & 4 & 1 & 2 \\
\hline LSD & 16 & 7 & 9 & 4 \\
\hline
\end{tabular}

Source: European School Survey Project on Alcohol and Other Drugs

Taken together, the results from both surveys indicate a consistent drop in cannabis use by school-going boys. For school-going girls a decrease in cannabis use was not consistently observed across both surveys. The increase in lifetime prevalence of drugs such as solvents, cocaine and heroin by both school-going boys and girls although small, present renewed challenges.

It should be stressed that the above prevalence rates are based on school-going children and do not provide any information on those not attending school. Little is known about the use of drugs among those not attending school in Ireland. In a small Dublin-based survey of those who had left school early but had returned to further education, Comiskey and Miller (2000) found that over half of the respondents had tried using drugs before they had left school and nearly three quarters had tried using drugs on or before the age of fifteen. It was noted that of those who had tried using drugs before they had left school, just under half stated that their drug use had affected them at least sometimes while they attended school. While the results from this particular sub-group of early school leavers do not necessarily reflect the wider group of early school leavers they do suggest higher rates of drug use among children and adolescents not attending school.

\section{Trends in Treatment for Problem Drug Use}

Drug treatment data are viewed as an indirect indicator of problem drug use. In Ireland, data on clients seeking treatment for problem drug use is recorded in the 
National Drug Treatment Reporting System. The National Drug Treatment Reporting System is co-ordinated by staff at the Drug Misuse Research Division of the Health Research Board on behalf of the Department of Health and Children. It was established in 1990 in the Greater Dublin Area and was extended in 1995 to cover other areas of the country.

The National Drug Treatment Reporting System data are used at national level to provide information on the characteristics of persons entering treatment, and on patterns of problem drug use, such as types of drugs used and consumption behaviours. Compliance with the National Drug Treatment Reporting System requires that one form be completed for each person who receives treatment for problematic drug use at each treatment centre in a calendar year. The main elements of the reporting system are:

- All cases treated - describes individuals who receive treatment for problematic drug use at each treatment centre in a calendar year

- Previously treated cases - describes persons who were previously treated for problematic drug use at any treatment centre and have returned to treatment in the reporting year, and also those individuals continuing in treatment from the preceding calendar year

- New cases treated - describes the sub-group of individuals who have never been treated previously for problem drug use.

In the case of the data for 'previously treated cases' there is a possibility of duplication in the database, for example, where a person receives treatment at more than one centre.

Between 1991 and 2000, 44,068 people were treated for problem drug use in Ireland and reported to the National Drug Treatment Reporting System. Of whom, $13,393(30 \%)$ individuals were treated for the first time for problem drug use. Of the 13,393 new cases, 10,529 individuals resided in counties Dublin, Kildare and Wicklow (which comprise the HSE Eastern Regional Area) while 2,864 resided in the counties outside the HSE Eastern Regional Area. The data for the two geographical areas (within and outside the HSE Eastern Regional Area) were collected over different time periods, and therefore, the analyses will be presented by geographical area. The data on individuals residing in the HSE Eastern Regional Area was collected between 1991 and 2000 while the data on individuals residing outside the HSE Eastern Regional Area was collected between 1996 and 2000. 


\section{Trends in Treatment for Problem Drug Use in the Health Service Executive Eastern Regional Area, 1991-2000}

From 1991 to $2000,10,529$ individuals were treated for problem drug use for the first time; of whom, 2,034 (19\%) of these were under 18 years old. The proportion of young problem drug users seeking treatment for the first time increased from 23\% in 1991 to $25 \%$ in 1996 and subsequently, decreased gradually to $11 \%$ in 2000 (Table 6). This indicates that the demand for treatment services among those aged under 18 years who lived in the HSE Eastern Regional Area has decreased between 1996 and 2000.

Table 6 Age of new cases living in the HSE Eastern Regional Area and reported to the National Drug Treatment Reporting System, 1991 to 2000.

\begin{tabular}{lllllllllll}
\hline Age & 1991 & 1992 & 1993 & 1994 & 1995 & 1996 & 1997 & 1998 & 1999 & 2000 \\
\hline$<=17$ years & 96 & 135 & 185 & 237 & 345 & 386 & 219 & 211 & 112 & 108 \\
$>=18$ years & 330 & 517 & 674 & 884 & 1,120 & 1,176 & 881 & 908 & 1,106 & 863
\end{tabular}

In order to describe problem drug users who lived in the HSE Eastern Regional Area who were aged under 18 years and sought treatment for the first time between 1991 and 2000 , selected socio-demographic and drug-using characteristics were examined.

- Of the 2,034 new cases under 18 years old, 247 (12\%) were aged between 10 and 14 years. The annual numbers of new cases aged between 10 and 14 years were small; therefore it is difficult to comment on the trend over the reporting period.

- Of the 2,018 new cases whose gender was recorded, $623(31 \%)$ were girls. The proportion of young girls seeking treatment for problem drug use increased from $28 \%$ in 1991 to $37 \%$ in 1997 and remained relatively stable between 1997 and 2000 .

- Of the 1,922 new cases for whom living status was recorded, 1,723 (90\%) lived with parents and family. The proportion of problem drug users aged under 18 years living with parents and family decreased from $95 \%$ in 1991 to $79 \%$ in 2000 . It is of note that 29 new cases (aged 17 years or less) were living alone with young children and an additional 25 were homeless between 1995 and 2000. 
- Of the 1,278 new young drug users for whom the age that they had left school was reported, 531 (42\%) had left school before the age of 15 years between 1991 and 2000. The proportion of young drug users who reported that they had left school early remained above one-third throughout the period under review.

Taken together, this data indicates that these young drug users seeking treatment for the first time had not achieved their educational potential and may live in an unstable environment. In addition, a small number of young drug users were living alone with their young children.

Between 1991 and 2000, the main problem drugs reported by new cases under 18 years old seeking treatment for the first time and living in the HSE Eastern Regional Area were opiates $(979,48 \%)$ and cannabis $(686,34 \%)$ and to a lesser extent volatile inhalants $(129,6 \%)$ and ecstasy $(115,6 \%)$. The most common main problem drug reported changed over time; in the early nineties cannabis was the most common main problem drug reported while in the mid-nineties opiates were the most common group of problem drugs reported and in the late nineties cannabis was once again the most common main problem drug reported.

Almost $65 \%(1,320)$ of young drug users seeking treatment for problem drug use for the first time reported using more than one drug. Of the 1,281 young persons who reported the name of the second problem drug used, cannabis $(353,28 \%)$, opiates (252, 20\%), benzodiazepines $(175,14 \%)$ alcohol $(159,12 \%)$ and ecstasy $(156,12 \%)$ were the most commonly used second drugs. The majority of young people commence illicit drug use with cannabis, ecstasy or volatile inhalants. Therefore, except for opiates, the profile of reported drug use by these young persons was as expected.

The high proportion of opiate users who sought treatment may indicate that opiate is a drug of initiation or a delay in seeking treatment until opiate dependent or the type of drug treatment services available. Dillon, in two separate studies, found that most opiate users used cannabis, volatile inhalants, hypnotic sedatives and/or ecstasy prior to their opiate use (Dillon 2001a; Dillon 2001b) though Dillon (2001b) reported a small number of young drug users had taken an opiate as their first drug.

Over one-fifth (433 of 1,972) of the young drug users reported having ever injected an illicit substance while $14 \%$ (274 of 1,969) were injecting at the time of seeking their first treatment. Overall, the proportion of young persons who reported ever injecting an illicit drug at their first treatment contact increased from $10 \%$ in 1991 to $26 \%$ in 2000. Several researchers have linked the risk of blood-borne viral transmission (in particular 
hepatitis C) among drug users with length of time injecting (Smyth et al 1995; Smyth et al 1998; Smyth et al 1999; Allwright et al 2000). This indicates that these young drug users have a high risk of contracting hepatitis $C$ if they continue to inject. Of note, injecting rather than smoking heroin increases the risk of overdose.

The median age of those who first used their main problem drug was higher than the median age of those who first used any illicit drugs. This indicates that opiates were not the first drug used by these young drug users. The median age of one of those who first used their main problem drug was examined for young drug users seeking treatment for the first time between 1995 and 2000 but the time to treatment has increased by six months between 1995 and 2000 (Table 7). This indicates continued early initiation of illicit drug use and an increasing delay in treatment seeking.

Table 7 Median ages of drug use and first treatment for new cases living in the HSE Eastern Regional Area and reported to the National Drug Treatment Reporting System, 1995 to 2000

\begin{tabular}{lcccccc}
\hline & 1995 & 1996 & 1997 & 1998 & 1999 & 2000 \\
\hline $\begin{array}{l}\text { Median age first } \\
\text { used any drug }\end{array}$ & 14 & 14 & 14 & 14 & 14 & 13 \\
$\begin{array}{l}\text { Median age first } \\
\text { used main drug }\end{array}$ & 15 & 15 & 15 & 15 & 15 & 14 \\
$\begin{array}{l}\text { Median age } \\
\text { first injected }\end{array}$ & 16 & 16 & 16 & 16 & 15 & 16 \\
$\begin{array}{l}\text { Median age first } \\
\text { treatment }\end{array}$ & 16 & 16 & 16 & 16 & 16 & 16 \\
$\begin{array}{l}\text { Time from first use } \\
\text { of main problem } \\
\text { drug to treatment } \\
\text { in years }\end{array}$ & 1 & 1 & 1 & 1.5 & 1.4 & 1.5 \\
\hline
\end{tabular}




\section{Trends in treatment for problem drug use outside the HSE, Eastern Regional Area, 1996-2000}

From 1996 to 2000, 2,864 individuals were treated for problem drug use for the first time, $629(22 \%)$ of whom were aged under 18. The proportion of young problem drug users seeking treatment for the first time decreased from 25\% in 1996 to $22 \%$ in 2000 (Table 8). This indicates that the demand for treatment services among those aged under 18 years who lived outside the HSE Eastern Regional Area has decreased marginally between 1996 and 2000.

Table 8 Age of new cases living outside the HSE Eastern Regional Area and reported to the National Drug Treatment Reporting System, 1991 to 2000.

\begin{tabular}{lccccc}
\hline Age & 1996 & 1997 & 1998 & 1999 & 2000 \\
\hline 17 years or less & 111 & 95 & 86 & 124 & 213 \\
18 years or more & 330 & 299 & 378 & 455 & 763 \\
\hline
\end{tabular}

In order to describe drug users who lived outside the HSE Eastern Regional Area who were under 18 years old and seeking treatment for the first time between 1996 and 2000, selected socio-demographic and drug-using characteristics were examined:

- Of the 629 new cases under 18 years old, 64 (10\%) were aged between 10 and 14 years. The annual numbers of new cases aged between 10 and 14 years were small but increased from seven (6\%) in 1996 to $27(13 \%)$ in 2000.

- Of the 623 new cases whose gender was recorded, one quarter (156) were girls. The proportion of young girls seeking first treatment for problem drug use increased from $21 \%$ in 1996 to $26 \%$ in 2000 .

- Of the 621 new cases for whom living status was recorded, 539 (87\%) lived with parents and family. Of note, $41(7 \%)$ young drug users were living alone with young children outside the HSE Eastern Regional Area between 1996 and 2000.

- Of the 305 new cases for which the age that they had left school was reported,115 (38\%) had left school before the age of 15 years between 1996 and 2000. The proportion of young drug users who reported that they had left school early increased from $28 \%$ in 1996 to $43 \%$ in 2000 . 
This data indicates that these young drug users seeking treatment for the first time have not achieved their educational potential and a number were caring for young children.

Between 1996 and 2000, the main problem drugs reported by new cases aged under 18 years seeking treatment for the first time and living outside the HSE Eastern Regional Area were cannabis $(428,68 \%$ ) and to a lesser extent ecstasy $(110,18 \%)$ and volatile inhalants $(53,8 \%)$. Cannabis was the most commonly reported main problem drug throughout the reporting period. Over three quarters of young drug users seeking first treatment for problem drug use reported using more than one drug. Of the 472 young persons who stated the name of their second problem drug, alcohol $(144,31 \%)$, ecstasy $(143,30 \%)$ and cannabis $(90,19 \%)$ were the most common second drugs reported. The majority of young people commence illicit drug use with cannabis, ecstasy or volatile inhalants. Therefore, the profile of drugs used was as expected.

Of the young drug users living outside the HSE Eastern Regional Area and seeking treatment for the first time between 1996 and 2000, only 19 reported opiates as a problem drug. Of the 617 new young drug users whose injector status was known, only $8(1 \%)$ reported injecting drugs in their lifetime.

The median age of first illicit drug use was examined for young drug users seeking treatment for the first time between 1996 and 2000 and it was noted that the age first using any illicit drug has remained stable over time while the time to treatment has increased marginally between 1996 and 2000 (Table 9). 
Table 9 Median ages of drug use and first treatment for new cases living outside the HSE Eastern Regional Area and reported to the National Drug Treatment Reporting System, 1996 to 2000 .

\begin{tabular}{lccccc}
\hline & 1996 & 1997 & 1998 & 1999 & 2000 \\
\hline $\begin{array}{l}\text { Median age first } \\
\text { used any drug }\end{array}$ & 14 & 14 & 14 & 14 & 14 \\
$\begin{array}{l}\text { Median age first } \\
\text { used main drug }\end{array}$ & 15 & 15 & 14 & 14 & 14 \\
$\begin{array}{l}\text { Median age } \\
\text { first treatment }\end{array}$ & 16 & 17 & 16 & 16 & 16 \\
$\begin{array}{l}\text { Time from first use } \\
\text { of main problem } \\
\text { drug to treatment }\end{array}$ & 1.6 & 1.4 & 1.7 & 1.4 & 1.9 \\
in years & & & & & \\
\hline
\end{tabular}

The median age of first drug use from 1998 to 2000 was the same as the median age of first using the main drug and this indicates that the first and main drug are likely to be the same (Table 9). The time interval between commencing use of the main problem drug and seeking treatment was longer than that reported by young drug users living in the HSE, Eastern Regional Area and increased by four months during the reporting period.

\section{Implications of Data}

At a fundamental level the data underlines the fact that attendances by children for drug treatment services are at a very high level and account for a very substantial portion of the workload of the addiction services. While Ireland's child and adolescent population is decreasing it is still the highest in the EU in terms of the percentage of total population.

Following a sizeable increase in the early to mid 1990s, the demand for treatment services among those aged under 18 years who lived in the HSE Eastern Regional Area has decreased substantially between 1996 and 2000 whereas the demand for treatment outside the HSE Eastern Regional Area has decreased marginally. 
Injecting drug use was rarely reported outside the HSE Eastern Regional Area. In the HSE Eastern Regional Area, the proportion of young persons who reported ever injecting an illicit drug at their first treatment contact increased substantially during the period under review. This indicates that these young injecting drug users have a high risk of contracting hepatitis $\mathrm{C}$ and overdose.

It is clear that the experience of drug services is one of a moving client population, changing demographics and evolving patterns of drug misuse. Evidence from school-based surveys would suggest that cannabis use in school-going boys is decreasing but such a trend is not consistently observed in school-going girls. Lifetime prevalence of drugs such as solvents, cocaine and heroin, although small in comparison to cannabis, are increasing for both school-going boys and girls.

Little is known about the use of drugs among those not attending school in Ireland. What evidence is available would suggest higher rates of drug use among children and adolescents not attending school. Research on this vulnerable group falls within the remit of the National Advisory Committee on Drugs and should be accelerated.

Young drug users seeking treatment for the first time have not achieved their educational potential and a small number of young drug users were living alone with their young children in Ireland. In addition, in the HSE Eastern Regional Area a small number live in an unstable environment. This points to serious child-care issues for both the adolescent parent(s) and their child(ren).

Outside the HSE Eastern Regional Area, the majority of young people sought treatment for problem cannabis use while within the HSE Eastern Regional Area, the majority of young people sought treatment for problem opiate use.

Polydrug use was commonly reported by these young drug users and this places an additional burden on treatment services.

The median age of first use of any drug was the same as the median age of first using the main problem drug outside the HSE Eastern Regional Area between 1998 and 2000 and this indicates that the first and main drug were probably the same. The median age of first used their main problem drug was higher than the median age of first using any drug in the HSE Eastern Regional Area indicating that opiates were not the first drugs used by these young drug users. 
The time interval between commencing the main problem drug and seeking first treatment increased throughout Ireland. The factors influencing this delay in seeking treatment require investigation. In the HSE Eastern Regional Area, the delay in seeking treatment may include lack of appropriate services for young persons or a service that caters for problem opiate use rather than the wider spectrum of illicit drugs used by young persons such as alcohol, cannabis, ecstasy and volatile inhalants. Outside the HSE Eastern Regional Area, it may indicate that cannabis (the main problem drug for the vast majority) takes a longer period of time to develop problems that negatively affect these young persons' health and welfare or that the addiction services have a backlog of cases.

The Group was conscious that data related to drug misuse needs to be interpreted with care. As noted above, a fall off in the numbers of young people presenting to drug treatment services could be caused by a number of factors other than reduced problem drug misuse. However, in overall terms the Group believes that the data reaffirms the relevance to many of the issues raised in the Group's work. In particular it suggests the need to focus on a number of key areas.

\section{Child Centred Services}

The Group is particularly concerned about the need for addiction services to address the specific needs of children and adolescents. During the Group's work, the need to ensure that children and adolescents are not disadvantaged by being treated in an adult-oriented framework was emphasised in a number of different ways.

- The work done with young people emphasised the need to create services which young people would be encouraged into and retained within, emphasising the importance of service design and staff training to being approachable to young people.

- Some service providers were of the view that separately locating young persons' services would be desirable, others gave this separate location less priority. There was general acceptance, however, of the need to avoid peer pressure and to prevent young people being negatively influenced by older people in a treatment context.

- It was accepted by the Group that the different numbers of young people presenting to services in different parts of the country, could require different approaches to meeting the specific needs of children and adolescents. 
Given that the experience of drug services is one of a moving client population, changing demographics and rapidly evolving patterns of drug misuse, considerable flexibility is required to respond to the challenges of problem substance misuse by young people.

- The surge in children presenting to treatment services in relation to heroin during the early to mid-1990s may be replicated in relation to other substance issues over the coming years. Cocaine use and excessive alcohol consumption are generating considerable concern at present. The challenge for drug services is to be flexible enough to respond to those changes in drug use through monitoring change and adaptability of staff.

- The increase in the number of female children and adolescents presenting to treatment services needs to be taken into account not just by treatment services but also in relation to obstetric and neonatal provision, social services, education and prisons.

- Most young people with serious drug problems live with their families. However a growing minority are homeless and the particular challenges that creates for successful treatment needs to be met through appropriate inter-agency working on their behalf.

\section{Prevention and Early Intervention}

It is clear from the literature that the risks of adolescent substance abuse are not spread uniformly through the general population. Rather, there are a number of "risk factors" which contribute towards such an outcome. Equally, there are protective factors which work to reduce the possibility of problematic substance abuse.

Amongst the risk factors which the Group felt were most relevant in the Irish situation were:

- Economic factors: problem drug misuse in Ireland is concentrated mostly on more economically deprived areas

- Behavioural and Environmental factors: in particular early school leaving, early onset of alcohol or drug use and association with substance using peers

- Family factors: including parental substance misuse, poor family management, homelessness 
- Psychological factors: especially mental health problems.

Amongst the protective factors which the Group felt were most relevant to the Irish context were:

- Supportive family environment

- Life-skills

- School connection

- Psychological well-being.

The Group felt that prevention and early intervention initiatives should focus primarily on developing and supporting protective factors in relation to those most at risk. It noted that within the National Drugs Strategy, Local Drugs Task Forces were charged with providing support to the areas most affected by problem drug use, while other specific actions in the Strategy sought to target risk factors and develop protective factors. For example, the Strategy emphasises supports for the school and non-school sector, the development of life-skills through Social, Personal and Health Education, and recognises the family and the community as significant contributors to tackling drug issues.

The Group felt that the prevention and early intervention initiatives set out in the Strategy specifically related to children and adolescents should be accelerated. In particular, the interaction between the judicial system and the health services should be more fully exploited with a view to preventing the escalation of problem drug misuse. Prevention and early intervention are key concepts embedded in a number of other policy documents: e.g. the Primary Care Strategy, the National Health Promotion Strategy, the Youth Homeless Strategy and the Eastern Regional Childcare Framework. Similarly, the risk and protective factors outlined are and have been transferable into other settings in policy development across children and family services including youth homeless services. 


\section{References}

Allwright S, Bradley F, Long J, Barry J, Thornton L and Parry JV. (2000) Prevalence of antibodies to hepatitis $\mathrm{B}$, hepatitis $\mathrm{C}$ and HIV and risk factors in Irish prisoners: results of a national cross sectional survey. British Medical Journal, 321, 78-82.

Comiskey CM and Miller RTH. (2000) Young people, drug use and early schoo leaving. Dublin: Department of Education and Science.

Dillon L (2001a) Drug Use among Prisoners: An Exploratory Study. Dublin: Health Research Board.

Dillon L (2001b) Drug Use as a Career: The Irish Heroin Users' Perspective. Thesis submitted for the degree Masters in Letters, University of Dublin.

Hibell B, Andersson B, Bjarnason T, Kokkevi A, Morgan M and Narusk A. (1997) The 1995 ESPAD Report. Alcohol and other drug use among students in 26 European countries. Stockholm: The Swedish Council for Information on Alcohol and Other Drugs (CAN), The Pompidou Group at the Council of Europe.

Hibell B, Andersson B, Ahlström S, Balakireva O, Bjarnason T, Kokkevi A and Morgan M. (2000) The 1999 ESPAD Report. Alcohol and other drug use among students in 30 European countries. Stockholm: The Swedish Council for Information on Alcohol and Other Drugs (CAN), The Pompidou Group at the Council of Europe.

Kelleher C, Nic Gabhainn S, Friel S, Corrigan H, Nolan G, Sixsmith J, Walsh O and Cooke M. (2003) The National Health and Lifestyle Surveys. Galway: Centre for Health Promotion Studies, National University of Ireland.

Smyth R, Keenan E, Dornan A, and O'Connor J. (1995) Hepatitis C infection among injecting drug users attending the national drug treatment centre. Irish Journal of Medical Science, 165(4), 267-268.

Smyth R, Keenan E and O'Connor J. (1998) Blood-borne viral infection in Irish injecting drug users. Addiction, 93(11), 1649-1656.

Smyth B, Keenan E and O'Connor J. (1999) Evaluation of the impact of Dublin's expanded harm reduction programme on prevalence of hepatitis $C$ among short term injecting drug users. Journal of Epidemiology and Community Health, 53, 434-435. 
Smyth, BP and O'Brien M European Addiction Research (2004) Children Attending Addiction Treatment Services in Dublin 1990 to 1999 10, 68-74. 


\section{CHAPTER THREE - LEGAL AND ETHICAL ISSUES}

\section{Background}

The terms of reference of the Group ask it to consider the legal and ethical issues surrounding the treatment of persons under 18 years of age presenting with serious drug misuse problems. The needs of young people who are homeless in this respect was raised as a matter of particular concern. Three sets of separate but interrelated issues were identified by the Group in this context. These were:

(i) The legal obligations of service providers towards children and young people who present with serious drug misuse problems;

(ii) The need to respect the legal and other rights of the children and young people presenting with serious drug misuse problems and of their families;

(iii) The legal mechanisms which can be utilised to ensure that children and young people presenting with serious drug misuse problems receive appropriate treatment.

\section{Legal Obligations of Service Providers}

In terms of the legal obligations of service providers, two main sets of issues were identified. The first related to the unique statutory responsibilities of the former Health Boards. The second was the legal and ethical responsibilities of service providers generally, especially once treatment has been initiated.

\subsection{Health Service Executive (formerly Health Boards)}

Section 3 of the Child Care Act 1991, as it applied to health boards defined a child as meaning a person under the age of 18 years, other than a person who is or has been married, provides that: -

"3-(1) It shall be a function of every health board to promote the welfare of children in its area who are not receiving adequate care and protection.

(2) In the performance of this function, a health board shall-

(a) take such steps as it considers requisite to identify children who are not receiving adequate care and protection and co-ordinate information from all relevant sources relating to children in its area; 
(b) having regard to the rights and duties of parents, whether under the Constitution or otherwise-

(i) regard the welfare of the child as the first and paramount consideration, and

(ii) in so far as is practicable, give due consideration, having regard to his age and understanding, to the wishes of the child; and

(c) have regard to the principle that it is generally in the best interests of a child to be brought up in his own family.

(3) A health board shall, in addition to any other function assigned to it under this Act or any other enactment, provide child care and family support services, and may provide and maintain premises and make such other provision as it considers necessary or desirable for such purposes, subject to any general direction given by the Minister under Section 69."

The Health Act, 2004 has established the Health Service Executive which now has responsibility for discharging statutory obligations, formerly the responsibility of the health boards, under the Child Care Act, 1991.

It is clear that the Act confers certain obligations, responsibilities and qualified entitlements on to health boards (now the Health Service Executive) in relation to the care of young people. Equally it is recognised that the extent and/or limits of those obligations, responsibilities and entitlements cannot be defined in a general way but must be considered on a case by case basis.

\subsection{All Service Providers}

All service providers, including the HSE (formerly the health boards), have ethical and legal responsibilities in relation to children and young people who they take into treatment.

\section{Rights of Service Users and Their Families}

All services must be provided in a way which respects the rights of service users and their families. As set out above, the 1991 Child Care Act requires health boards (now the HSE) to take into account the rights and duties of parents, prioritise the welfare of the child and give due consideration to the wishes of the child. Similar considerations apply to all service providers. 


\section{LEGAL AND ETHICAL ISSUES}

\section{Consent}

A particular issue which arises in this context is the question of consent to treatment.

The Group was very conscious of the legal dilemmas facing those who provide services to under 18 year olds. The various situations which arise in this context were the subject of legal opinion requested by the Group and include:

- the capacity of 16-18 year olds to consent to treatment

- the capacity of under 16 year olds to consent to treatment

- the issue of consent in respect of under 18 year olds in care.

Failure by a service provider to obtain appropriate consent to treatment in any of these cases could result in the procedure being regarded as a trespass, leaving the service provider open to the risk of legal action being brought against him/her by the patient or their parent/guardian.

\subsection{Capacity of 16-18 year olds to consent to treatment}

Section 23(1) of the Non-Fatal Offences Against the Person Act 1997 provides that:

"The consent of a minor, who has attained the age of 16 years to any surgical, dental or medical treatment, which in the absence of consent would constitute a trespass to his or her person, shall be effective as it would be if he or she were of full age; and where a minor has by virtue of this section given an effective consent to any treatment it shall not be necessary to obtain any consent for it from his or her parent or guardian."

Psychiatric treatment and other forms of treatment by non-invasive means appear to fall within the ambit of this section.

The Act effectively reduces the minimum age for the giving of consent for any surgical, dental or medical treatment to 16 years, thereby negating the need for parental consent in such cases. As a result the consent of a 16-18 year old to treatment cannot be overridden by the objections of a parent or guardian.

It must, however, be borne in mind that the service provider remains obliged to adhere to ethical norms and to ensure that the consent of the young person is a fully informed one. Where the 16-18 year old lacks the knowledge and understanding necessary to give an informed consent to treatment, the consent of their parent or guardian should be sought. Furthermore, the consent of a parent or guardian will 
suffice in cases where a 16-18 year old refuses to consent to treatment.

Service providers should also be aware that where consent is being sought from a 16-18 year old in respect of a procedure which does not constitute a treatment or diagnosis it is advisable to also seek the consent of a parent or guardian.

\subsection{Capacity of under 16 year olds to consent to treatment}

Patients under the age of 16 years do not fall within the scope of Section 23 of the Non-Fatal Offences against the Person Act 1997. Therefore, the consent of a parent or guardian is required for all forms of treatment of under 16 year olds in the absence of a legal order to the contrary.

The need to obtain consent may of course present problems for service providers in cases where the young person is unwilling to have the fact of the treatment process revealed to a parent or guardian. This, however, does not obviate the obligation of the service provider to obtain consent in such cases.

\subsection{Consent in respect of under 18 year olds in care}

\subsubsection{Under 18 Year Olds Who Are the Subject of a Care Order}

Under the Child Care Act 1991, the HSE, (formerly a health board) may consent to any necessary or psychiatric examination, treatment or assessment of a child who is in its care under a formal care order which has been made by the Court under Section 18 of that Act. Good practice would, however, indicate that parental consent should first of all be sought. A refusal by the parents to consent does not, however, affect the validity of any consent given by the HSE.

In relation to 16-18 year olds who are the subject of care orders, Section 23 of the Non-Fatal Offences Against the Person Act 1997 applies. If the 16-18 year old is unable to give an informed consent the consent of the HSE is required. It may also be wise to consult the child's parents. In circumstances where the 16-18 year old is unwilling to consent to treatment the HSE can apply to the Court for directions in the matter.

\subsubsection{Under 18 Year Olds in Voluntary Care}

In relation to under 16 year olds in voluntary care the consent of the young person's parents is required. In the event of this consent being refused the HSE may seek directions in the matter from the Court under Section 47 of the Child Care Act, 1991. As regards those in voluntary care aged between 16 and 18 years Section 23 of the 


\section{LEGAL AND ETHICAL ISSUES}

Non-Fatal Offences Against the Person Act 1997 applies. Where doubts exist as to whether the young person is capable of giving an informed consent to treatment, the consent of a parent or guardian should be sought. If this consent is not forthcoming the HSE may seek directions from the Court in the matter.

\subsubsection{Under 18 Year Olds Who Are the Subject of an Interim/Emergency Care Order}

In the case of under 18 year olds who are the subject of interim/emergency care orders the HSE may only consent to treatment by making an application to the District Court under Section 47 of the Child Care Act, 1991. In all other circumstances the consent of either the young person or their parents is necessary.

\section{Refusal of Treatment by Young Person}

A particular difficulty for service providers and the HSE arises in cases where a young person is unwilling to undergo treatment or to adhere to the treatment programme.

Hitherto, the Mental Treatment Act, 1945 might have been of some assistance in such circumstances. The Act allows for certification for addiction, thereby permitting the detention of an addict over 16 years of age for up to six months preventative or curative treatment. However, this Act will effectively be repealed by the Mental Health Act, 2001. Section 8 of this Act excludes addiction to drugs or intoxicants as a basis for involuntary admission to approved centres, but persons who have a psychiatric condition in addition to an addiction to drugs or intoxiants can be admitted on the basis of their psychiatric condition. (It should be noted that this section has not been commenced at the current time).

While the Child Care Act, 1991 as amended by Section 16 if the Children Act, 2001, provides a means for the detention of a small number of non offending children in need of special care or protection in a special care unit as a last resort following a family welfare conference, this process excludes detention in special care for the purposes of medically supervised detoxification in accordance with criteria set by the Special Residential Services Board.

While it is noted that the High Court has on occasion made orders detaining a young person where a real and substantial risk exists to the life and welfare of the 
young person as a result of their drug misuse complex medical, ethical and policy issues arise in this regard.

\section{Compliance with Treatment Programmes}

In the area of drug treatment, many programmes offer a treatment package comprising medical and other supports. In some situations, difficulties may arise where clients do not wish to co-operate with the full programme. In such circumstances, there may be an ethical and legal obligation to continue treatment. However, it may not always be appropriate to continue treatment within a particular programme.

An overall treatment programme may, for example, consist of both social/educational and medical programmes. Where an individual refuses to take part in the social/education aspect of the programme this may influence others to do likewise thereby considerably reducing the efficacy of the treatment programme as a whole. In situations of this nature it may be advisable to transfer the young person in question to another programme as a complete suspension or termination of treatment might be at variance with the legal and ethical obligations of the service provider.

\section{Election to Discontinue Treatment}

Finally, it should be noted that a service provider ceases to be under a legal or ethical duty to a young person once that person elects to discontinue treatment.

\section{Conclusions}

The Group acknowledged the difficulties for statutory, voluntary and community personnel working in this area, particularly in relation to the issue of consent.

In this regard the Group noted that family involvement in the treatment of a child or adolescent drug misuser leads to better outcomes for the child or adolescent. As such the first priority for treatment services was to try to secure the involvement of the client's family. However, it was accepted that it was not always possible to secure family involvement or indeed parental consent.

The Group noted that the legislation in place allowed persons aged 16 and 17 to 


\section{LEGAL AND ETHICAL ISSUES}

consent on their own behalf to certain treatments. However, there appeared to be some doubts as to whether the Courts would accept that such consent could apply to drug treatment. In this context it was felt that the UK concept of "Gillick competence", whereby professionals could assess whether a young person was competent to give informed consent on his/her own behalf or not, could play an important role.

The Group considered that even where consent is not required from parents/guardians when prescribing substitute treatment it is advisable to include parents within the treatment process in order to ensure the most favourable outcomes.

In view of the complexity of the issues involved, the Group felt that substitution treatment for under 18 year olds should not be initiated outside a specialist context. 


\section{CHAPTER FOUR - TREATMENT MODEL}

\section{Background}

In considering what was the appropriate model for the delivery of services to young people presenting with problem drug misuse, the Group considered the evidence which it gathered from the literature review, from the input of professionals working in the field, from the available data and from service users. It concluded that in order to meet the needs of young people considerable emphasis needed to be placed on an integrated approach to the development of substance misuse services. In particular, the Group felt that the models developed by the Health Advisory Service (HAS) in the UK, adapted as necessary to an Irish context, would best deliver effective services to young people presenting with problem drug misuse.

This chapter considers the psychological background to substance misuse during adolescence and outlines how the tiered model for service delivery developed by the HAS and favoured by the Group for providing services to the young people affected could operate in an Irish context.

\section{Substance Misuse during Adolescence}

Adolescence is one of many stages during the lifecycle. It bridges the gap between childhood and adulthood. During this period, a person moves from a state of major dependence on the family towards a state of being able to operate as an independent functioning adult in society. The key change that permits this progression is a development in cognitive functioning. Children aged seven to eleven years demonstrate a concrete style of thinking, seeing the world in 'black and white'. By aged twelve, they begin to develop what is termed 'formal operational thinking'. This permits them to deal with more abstract concepts, to hypothesise and to use logic to solve abstract problems. They develop a more sophisticated awareness of their own emotional state. In tandem with this, their capacity to empathise grows as they learn to read and predict the emotional responses of others. They increase in their ability to correctly interpret the social subtleties of both verbal and non-verbal communication.

These psychological or cognitive changes permit the adolescent to develop more sophisticated friendships and greater independence from family. Although family remain important, the relative importance of peer relationships grows. The 
adolescent acquires a greater sense of their own identity and is faced with the dilemma of choosing the type of person that they want to become. This usually involves experimentation with different images or ways of behaving until they find an identity that 'fits'. This may involve engaging in some risk behaviour, often with friends. Parental values may be overtly or covertly challenged and opposed. Although often temporarily questioned or discarded, young people tend to return to values that are very similar to their parents' values by the end of adolescence.

As well as being the site where the adolescent obtains an academic education, school also provides the semi-protected milieu in which the adolescent learns how to interact with peers and the wider world. Experience of a broad range of social situations usually ensures that the adolescent develops a broad range of problem solving styles. They will thus be equipped to cope with an infinite range of complex social circumstances.

In summary, changes occur in brain functioning that permit the adolescent to think in a more abstract manner. These advanced cognitive skills allow the adolescent to interact with the world in a more independent manner. Increased interaction with a widening world provides the adolescent with the opportunity to practice how to best use their new cognitive skills. Learning how to use these skills then permits them to effectively and independently function in the complex social world of adults.

In early adolescence, the adolescent will often use an avoidant coping style when faced with social difficulty, e.g. retreating into their bedroom and listening to loud music when facing difficulties with peers or family. Later in adolescence, the same problems are likely to be dealt with in a more proactive manner, e.g. talking directly to their peer or seeking the assistance of an intermediary to negotiate difficulties with parents.

Just as infants vary greatly in the pace at which they learn to walk and talk, adolescents acquire the competencies necessary for effective adult functioning at very different rates. Normal development by an adolescent can be influenced by both intrinsic and extrinsic factors. Intrinsic factors include a delay in the brain changes that permit the 'formal operational thinking' described above. Extrinsic factors include lack of opportunity in one's own environment to practice using the newly acquired cognitive skills in a variety of social settings. This could happen in situations where a young person had minimal contact with peers due to being unable to attend school. 
Substance use may form part of the repertoire of risk behaviours in which adolescents tend to engage. They may be curious about how substances will affect their behaviour or thinking. Alcohol and drugs can induce a very wide range of feelings. For example, they can induce a sense of calmness, increase energy, enhance confidence or alter the way in which sensations are experienced. The adolescent may experience such phenomena as pleasant or unpleasant.

Some adolescents may turn to drugs or alcohol as an avoidant method of coping with life's difficulties. They may choose alcohol or drug intoxication as a method 'to switch off' or 'to make problems go away'. Regular use of drugs or alcohol will reduce the opportunity for the adolescent to learn alternative problem solving strategies. If their drug or alcohol use causes them to finish education early their difficulties may be compounded as they will miss out on the healthy social learning environment which school provides. This may further reduce their ability to acquire and develop the adaptive coping strategies and social problem solving styles that are necessary for healthy adult functioning in society.

Adolescents who are slower to develop the complex social skills necessary to interact effectively with peers and the wider world are more at risk of turning to drug or alcohol use. They may use alcohol or drugs to mask their anxiety in social situations or they may use these substances in an attempt to demonstrate their 'maturity' to peers. However, it would be wrong to assume that a 'lack of confidence' is a universal problem among teenagers who use drugs. Indeed, a personality profile that includes excessive confidence, sensation seeking and substantial risk taking is also associated with progression to drug misuse.

Problematic drug or alcohol use therefore demonstrates a complex interaction with normal adolescent development. Atypical patterns of development may place a teenager more at risk of addiction. Conversely, drug and alcohol misuse can themselves cause a delay in, or a deviation from, normal adolescent development. As a drug or alcohol problem grows, the young person is likely to find himself or herself in a progressively more deviant environment, e.g. in the company of delinquent peers, out of school or in prison. These environments promote a social interactional style that is likely to perpetuate a further delay in the acquisition of the skills appropriate to survival in 'mainstream society'. These issues highlight the potentially massive damage which problematic drug use can inflict on a young person during this crucial stage of development. They also demonstrate why adolescent addiction services require separate and specific services that can detect, manage and correct deviations in adolescent development that are a cause or a consequence of an adolescent's drug or alcohol use. 


\section{Principles of Drug Services for Young People}

In seeking to structure services to deliver an appropriate response, the HAS identified three key principles which should underpin all service delivery, namely that services for children and adolescents should be child-centred, comprehensive and competent.

\subsection{Child-centred}

In an Irish context it is clear that services should be child-centred, taking into account the specific needs of children and young people, their age and maturity, facilitating access to services and explaining and involving the young person and their parents or guardians in their participation in treatment.

\subsection{Comprehensive}

It is also essential that the full range of drug related interventions including drug education, prevention and treatment, be available to meet young people's needs. The treatment needs of many adolescent substance misusers will cross a range of services including drug-specific and non drug-specific services. It is essential that the model for service delivery be able to deliver that range of services in an integrated and effective way. In that context the group felt that care planning and key working appeared to be valuable approaches within this field.

\subsection{Competent}

As discussed in Chapter 3, there are complex legal and ethical issues surrounding the provision of drug treatment to children and adolescents. Services need to be aware of legal requirements, child protection issues, confidentiality procedures and other issues as they apply to this client group. Staff need to be competent in working with young people and to have access to the relevant expertise in relation to substance abuse either individually or as part of a team.

\section{National Children's Strategy}

The Group is committed to respecting the principles set out in the National Children's Strategy. The three goals of the Children's Strategy are

(i) Children will have a voice in matters which affect them and their views will given due weight in accordance with their age and maturity

(ii) Children's lives will be better understood: their lives will benefit from 


\section{TREATMENT MODEL}

evaluation, research and information on their needs, rights and effectiveness of services

(iii) Children will receive quality supports and services to promote all aspects of development.

The Group believe that their recommendations reflect fully the application of the three goals of the Children's Strategy to the area of substance misuse.

\section{Tiered Model of Treatment}

The Group believe that the tiered model developed by the HAS and adapted to an Irish context provides a solid framework for a multi-disciplinary approach to service delivery which would enable the necessary collaboration and co-ordination required to tailor treatment to the needs of young people presenting with problem drug misuse.

In an Irish context, the four tiers may be interpreted as follows:

Tier 1

Tier 1 comprises services which have contact with young people but which do not have specialist expertise in either adolescent mental health or addiction. In essence these are generic services such as education, youth and family services having direct access to young people and are suitable places to provide certain front-line interventions. Those involved include teachers, social services, police, probation and welfare, primary care service providers, community and family groups. The services provided for the general population of young people include substance misuse education, information and referral to support services. The type of adolescent accessing these services would be those considering or commencing experimentation with drugs or alcohol.

\section{Tier 2}

Tier 2 comprises services which have specialist expertise in either adolescent mental health or addiction, but not both. By their nature they will be in a position to offer some supports to young people who may be vulnerable to drug misuse problems. The people involved include GPs trained in addiction, Juvenile Liaison Officers, Local and Regional Drugs Task Forces projects, home school liaison, youth homeless services, Youthreach and drug treatment centre staff. The services provided for vulnerable young people include drug related prevention and targeted 
education, advice and support and counselling. The type of adolescent accessing this service would be those who are abusing alcohol or drugs and encountering some problems as a result.

\section{Tier 3}

Tier 3 comprises services which have specialist expertise in both adolescent mental health and addiction, i.e. multi-disciplinary teams comprising people with a speciality in adolescent addiction. The essential feature of Tier 3 is the co-ordination of services to provide child-centred, comprehensive treatment to young people presenting with serious drug problems. It is the bringing together of the multi-disciplinary team which provides the necessary expertise in adolescent addiction through the particular expertise of individual members. Not all individuals in the team will be experts in adolescent addiction: indeed many if not most may be working part-time in Tier 2 services.

A Tier 3 team must have access to the competencies needed to deliver such services, including access to expertise in the following:

- medical treatment options for addiction disorders (e.g. child psychiatrist or psychiatrist registrar or GP)

- treating co-morbid disorders (e.g. child psychiatrist or psychiatrist registrar)

- expertise in child protection issues (e.g. social worker)

- outreach (e.g. experienced outreach worker)

- assessment of development issues (e.g. child psychiatrist or psychiatrist registrar, clinical psychologist)

- delivering individual and group pyschotherapeutic interventions (e.g. clinical psychologist, child or addiction counsellor or nurse or child-care worker)

- expertise in systemic/family therapy (e.g family therapist).

The type of adolescent accessing this service would be experiencing substantial problems secondary to drug or alcohol abuse, or experiencing drug or alcohol dependence. Within this context, the Group stressed the value of a key-worker maintaining an on-going relationship with the client throughout his/her period of care.

Tier 4

Tier 4 services have specialist expertise in both adolescent mental health and addiction and the capacity to deliver brief but very intensive treatment, e.g. in-patient or day hospital. At present these services are provided in Cuan Dara, The 


\section{TREATMENT MODEL}

Drug Treatment Centre Board, etc. The type of adolescent accessing this service would be experiencing drug or alcohol dependence with severe associated problems.

A table summarising the key features of this Four Tier Model of Adolescent Addiction Treatment is set out on page 48. 


\section{Four Tier Model of Adolescent Addiction Treatment}

\begin{tabular}{|c|c|c|c|c|c|c|}
\hline & Specialist Skills & \begin{tabular}{|c|} 
Type of \\
Adolescent \\
accessing service
\end{tabular} & $\begin{array}{c}\text { Type of } \\
\text { intervention for } \\
\text { addiction } \\
\text { difficulties }\end{array}$ & $\begin{array}{l}\text { Intervention } \\
\text { delivered by }\end{array}$ & $\begin{array}{c}\text { Examples of } \\
\text { services at this } \\
\text { Tier * }\end{array}$ & $\begin{array}{c}\text { Intensity and } \\
\text { Duration }\end{array}$ \\
\hline Tier 1 & $\begin{array}{l}\text { Specialist skills } \\
\text { in neither } \\
\text { adolescent } \\
\text { mental health } \\
\text { nor addiction }\end{array}$ & $\begin{array}{l}\text { Considering or } \\
\text { commencing } \\
\text { experiment with } \\
\text { drugs or alcohol }\end{array}$ & $\begin{array}{l}\text { Basic advice } \\
\text { Onward referral }\end{array}$ & An individual & $\begin{array}{l}\text { Teacher, GP, } \\
\text { Probation officer, } \\
\text { Youth Worker, } \\
\text { A\&E, nurse, } \\
\text { social worker }\end{array}$ & $\begin{array}{l}\text { Low intensity } \\
\text { and on-going }\end{array}$ \\
\hline Tier 2 & $\begin{array}{l}\text { Specialist skills } \\
\text { in either } \\
\text { adolescent } \\
\text { mental health } \\
\text { or addiction }\end{array}$ & $\begin{array}{l}\text { Abusing drugs or } \\
\text { alcohol and } \\
\text { encountering } \\
\text { some problems } \\
\text { with same }\end{array}$ & $\begin{array}{l}\text { Basic counselling } \\
\text { Brief intervention } \\
\text { Harm reduction }\end{array}$ & An individual & $\begin{array}{l}\text { Child and Family } \\
\text { Service, Addiction } \\
\text { service, Teen } \\
\text { Counselling, JLO, } \\
\text { Local or Regional } \\
\text { Drugs Task Force } \\
\text { projects, home } \\
\text { school liaison } \\
\text { officer, } \\
\text { Youthreach, } \\
\text { educational } \\
\text { psychologist }\end{array}$ & $\begin{array}{l}\text { Low intensity } \\
\text { and medium } \\
\text { term duration }\end{array}$ \\
\hline Tier 3 & $\begin{array}{l}\text { Specialist skills } \\
\text { in both } \\
\text { adolescent } \\
\text { mental health } \\
\text { and addiction }\end{array}$ & $\begin{array}{l}\text { Substantial } \\
\text { problems due to } \\
\text { drug or alcohol } \\
\text { abuse }\end{array}$ & $\begin{array}{c}\text { Specialist } \\
\text { addiction } \\
\text { counselling } \\
\text { Family therapy } \\
\text { Group addiction } \\
\text { therapy } \\
\text { Substitution } \\
\text { treatment }\end{array}$ & $\begin{array}{l}\text { A multi- } \\
\text { disciplinary } \\
\text { team }\end{array}$ & $\begin{array}{c}\text { The specialist } \\
\text { adolescent } \\
\text { addiction service }\end{array}$ & $\begin{array}{l}\text { High intensity } \\
\text { and short to } \\
\text { medium term } \\
\text { duration (1-6 } \\
\text { months) }\end{array}$ \\
\hline Tier 4 & $\begin{array}{l}\text { Specialist skills } \\
\text { in both } \\
\text { adolescent } \\
\text { mental health } \\
\text { and addiction }\end{array}$ & $\begin{array}{c}\text { Drugs or alcohol } \\
\text { dependence with } \\
\text { severe associated } \\
\text { problems }\end{array}$ & $\begin{array}{c}\text { Specialist } \\
\text { addiction } \\
\text { counselling } \\
\text { Family therapy } \\
\text { Group addiction } \\
\text { therapy } \\
\text { Substitution } \\
\text { treatment }\end{array}$ & $\begin{array}{l}\text { A multi- } \\
\text { disciplinary } \\
\text { team }\end{array}$ & $\begin{array}{c}\text { Specialist } \\
\text { in-patient or day } \\
\text { hospital } \\
\text { adolescent } \\
\text { addiction services }\end{array}$ & $\begin{array}{l}\text { Very high } \\
\text { intensity and } \\
\text { short duration } \\
\text { (2-6 weeks) }\end{array}$ \\
\hline
\end{tabular}

*Tiering only refers to adolescent adiction assessment and treatment; for example services may specialise in areas such as child mental health, crime reduction, child welfare etc. but no addiction. 


\section{TREATMENT MODEL}

\section{Operation of the Tiered Model}

Within the overall multi-level structure, close co-operation between the four tiers will be essential. For example, staff working at Tier 3 would be expected both to work closely with and support interventions delivered by Tier 1 and Tier 2 services and to support the interventions delivered at Tier 4 . In terms of knowledge-sharing, training and development, it is to be expected that Tier 3 and Tier 4 service providers would provide services to Tier 1 and Tier 2 service providers. In this context the development of effective partnerships, within and between the tiers is of utmost importance, as is the development of appropriate training and policy frameworks (such as the School Substances Use Policy) to support each of the Tiers.

From the point of view of an individual client, it is clear that he/she will progress through different tiers, depending on the severity of the treatment need. A fundamental principal of treatment for adolescents is that intervention should be at the lowest level appropriate to their circumstances when presenting for treatment.

In essence, this model of treatment delivery requires explicitly establishing the networks required to deliver targeted and appropriate services to children and adolescents presenting with problem drug misuse. Its success relies heavily on the effective sharing of information, pooling of resources and development of a concerted focus amongst the various statutory and non-statutory bodies which will interact with an individual child or adolescent.

The Group felt strongly that the services which existed on the ground tended to fall into Tiers 1, 2 or 4 and that the greatest need in terms of developing this model of service delivery was in Tier 3. The Group also noted that the development of Tier 3 services could appropriately evolve in different ways within and outside the HSE Eastern Regional Area. 


\section{ACCESS TO SERVICES}

\section{CHAPTER FIVE - ACCESS TO SERVICES}

\section{Background}

Access to services was an important issue for participants in the Service User Group discussions and in the feed-back from service providers themselves. Three key themes were the ability of services to attract and retain young people into services, the frequent interaction of these young people with other services and the perceived lack of certain types of services of particular relevance to this client group.

The Group noted that a wide range of services were available across the country, as is clear from the mapping of services summarised in Appendix II. It acknowledged that in the context of resource constraints, priority needed to be given to developing the tiered treatment model adapted to the circumstances of the treatment population.

At the same time, the Group felt that it should highlight key priorities in relation to service design and modes of treatment provision which would need to be incorporated into the treatment model.

\section{Service Design}

There was a strong perception among under 18 year old drug misusers of a lack of access to services catering for and suitable to their needs both within and outside the HSE Eastern Regional Area.

The Group was particularly concerned that a failure to attract this cohort into services would have serious consequences for the harm done to problem drug misusers. Specifically, it was acknowledged that delayed intervention could allow the problem drug misuse to be exacerbated and could lead to increasingly risky behaviours (e.g. moving from smoking to injecting heroin).

The Group agreed that services should:

- strive to be adolescent specific, but didn't need to be addiction specific

- be local and accessible

- have multiple disciplines available on-site

- be able to offer assessment, treatment and aftercare. 
In this context, the Group felt that establishment of adolescent specific services within the HSE Eastern Regional Area needed to be progressed as a matter of urgency. The key factor in this regard was identified as the establishment of properly resourced multi-disciplinary team(s) capable of supporting existing services and of developing new services within existing physical structures, for example general adolescent services, health centres, etc.

At the same time the Group was conscious of the need to address service access outside the HSE Eastern Regional Area, where the smaller numbers of drug misusers raise additional challenges as regards the availability of adolescent - specific accessible addiction services. However, the Group was strongly of the view that the tiered model can be adapted to suit circumstances outside of the HSE Eastern Regional Area and felt that the Regional Drugs Task Forces should be resourced to contribute to the creation of the treatment networks required. In particular the Group felt that funding should be made available to Regional Drug Task Forces outside the HSE Eastern Regional Area to provide for the appointment of a person to look at the links and gaps in the existing service.

\section{Interaction with Other Services}

Young people with problem drug use can interact with a wide variety of agencies in addition to the drug treatment services. The Group felt that greater inter-agency working in terms of approach and care pathways could be achieved, particularly through appropriate participation in the tiered service delivery model. Integration would yield considerable benefits, both for the young people themselves and in terms of freeing up resources through more effective, co-ordinated and targeted interventions.

Services of particular interest in this context include:

- General child-care services. There was concern in the Group that the potential for integration between drug services and generic children and family services was not being realised. For example the overlap between youth homelessness and young people who misuse drugs is well documented and so the potential to harness resources, skills and expertise across these two areas could achieve real integration.

- Mental Health Services. Access to services by young people, particularly 16 to 18 year olds, was identified as a significant issue by the Group. A need to standardise roles and responsibilities in relation to young people with mental health problems is a significant issue, particularly in relation to those 


\section{ACCESS TO SERVICES}

presenting with problem drug misuse who require psychiatric assessment and/or treatment, particularly in the absence of consultant-led psychiatric services specialising in addiction.

- The Second Report of the Working Group on Child and Adolescent Psychiatry which was published in June, 2003, contains proposal for the development of the psychiatric services for 16-18 years olds. It recommends that, in the further development of the Child and Adolescent Psychiatric Service, priority should be given to the recruiment in each HSE area of a Consultant Child and Adolescent Psychiatrist with a special interest in the psychiatric disorders of later adolescence. The Working Group's report further recommends that arrangements should be made with the relevant Adult Psychiatric Services for the admission to acute psychiatric units of persons aged 16-18, under the care of the Consultant Child and Adolescent Psychiatrist with a special interest in the psychiatric disorders of later adolescence, where such a Consultant is available.

- The report emphasises the importance of co-operation and close liaison between child and adolescent psychiatry and adult mental health services and suggest that the current arrangements, whereby the adult services provide a service to the population of their catchment area, including the 16-18 age cohort, should continue on an interim basis.

- Homeless Services. The Group felt that the addiction services in each HSE Area should work closely with the homeless services in drawing up and implementing a homeless strategy for each local area.

- Criminal Justice Services. The Group noted that links between community drug treatment, probation and welfare and prison services were vital in respect of young people under the care of each of those services.

- Education and Training Services. The Group noted that an appropriate balance needs to be struck between treatment and prevention particularly in the context of young people and substance misuse.

The Group felt that greater co-operation and integration between the various services which young people availed of would contribute to a better outcome for young people and their families and communities. It considered that the delivery of the tiered model could facilitate this approach, provided that the service providers in the different services were committed to the approach.

Greater co-ordination of the efforts of the wide range of bodies involved in funding and delivering services in this area could also potentially free up existing resources to address the issues in a more comprehensive way. 


\section{Treatment Provision}

Action 49 asks the Group to consider issues such as the availability of appropriate residential and day treatment programmes, education and training rehabilitative measures and harm reduction responses for young people. As noted above, the existence of a broad range of these services is apparent through the mapping exercise. At the same time, service users and providers have expressed some concerns in relation to the availability of services.

\subsection{Residential and Day Treatment Programmes}

The Group identified, as a key priority, the need for adequate residential and day treatment catering for young people and designed in a way appropriate to their needs. It was felt that several models of good practice existed within the current constellation of services, which should be shared amongst services. It was agreed that services should be client-driven rather than provider-driven and that where needs changed service providers should be required to change to accommodate them.

Even in situations where a young person has a substantial drug or alcohol problem, residential treatment is rarely necessary. There is a misconception among the general public that residential treatment of addiction has a very successful outcome. Research in Ireland and elsewhere indicates that this is not the case. There are high rates of relapse following in-patient treatment. However, in circumstances where a young person's needs are so complex and substantial that they cannot be met on an out-patient basis, there is a definite role for in-patient treatment as part of an overall plan, which should also incorporate out-patient after care following the in-patient episode.

\subsection{Education and training measures}

The need for training, education and support for young people, for their parents and for service providers was identified as an important issue. Education and training initiatives need to be appropriate and supported by resource materials relevant to the client group, especially where the young people or parents concerned come from special needs groups. In this context the Group stressed the importance of general life skills training for young people at risk, appropriate screening and referral and collaborative working between Social, Personal and Health Education teachers and youth and community workers.

Many young people who develop substantial drug or alcohol problems have a history of poor educational attainment. Once an addiction treatment service has assisted an individual in stopping their drug or alcohol use, attention should shift 


\section{ACCESS TO SERVICES}

towards addressing their educational and training needs. Addressing these needs will lead to a situation whereby there is greater structure in the young person's day and greater contact with non-delinquent and non-drug using peers. It will also provide the teenager with educational and practical skills to improve job prospects etc. The provision of training and educational programmes that attract and retain such teenagers is a challenge to the Department of Education and Science and to agencies such as FÁS and Local Employment Schemes. It is important that training and education services do not exclude teenagers with a history of addiction problems. Good communication and inter-agency working between the Adolescent Addiction Service and the training and educational programmes in its locality are necessary. These services should be mutually supportive.

\subsection{Rehabilitation}

The Group emphasised the importance of rehabilitation and aftercare for young people. Rehabilitation services need to address the needs of young people and to have effective links into treatment centres. Flexibility in service provision was felt to be a key component of delivering a client based service.

The goal of rehabilitation is to reintegrate the teenager with drug or alcohol problems back into the community. Wherever possible, efforts should be made to link that young person into mainstream education and training programmes as described in the previous section. Generally, the needs of teenagers who develop drug and alcohol problems with regard to rehabilitation are not substantially different to the needs of other teenagers who have dropped out of school, those with conduct problems or those with contact with the criminal justice system. It is only a minority of teenagers with drug or alcohol problems who will require access to rehabilitation programmes that are specifically reserved for those with addiction. Where addiction specific rehabilitation programmes exist, they should strive to (re-)integrate their participants into generic training/education programmes as soon as is practical.

\subsection{Harm Reduction Responses}

Different views have been expressed concerning harm reduction approaches as they apply to young people presenting with problem drug misuse. In particular, the role of methadone in the treatment of young persons gave rise to differing views. The Group felt that substitution treatment should only be prescribed to young persons within a specialist context and should be considered as only a short term solution. The need for needle exchange services for under 18 year olds who are injecting drug users was also considered by the Group. The Group felt that such services were essential for young people given the risks inherent 
in needle-sharing. However, such services should only take place where possible in the context of a broad treatment regime. 


\section{CONCLUSIONS AND RECOMMENDATIONS}

\section{CHAPTER SIX - CONCLUSIONS AND RECOMMENDATIONS}

The appropriate treatment for young people presenting with problem drug misuse includes a range of medical, psychological and social supports. The Four Tiered Model for service delivery being recommended by the Group is expected to provide a realistic, flexible and adaptable framework within which those supports can be delivered to children and adolescents with serious substance misuse problems.

The Group's conclusions can be grouped into four broad categories: patterns of serious drug misuse amongst children and their implications, legal and ethical issues, model for service delivery and access to services.

\section{Patterns of Drug Misuse and Their Implications}

The Group recommends that drug treatment services should be child-centred, with an emphasis on service design which encourages and retains young people in treatment and rehabilitation services.

The Group recommends that services be delivered on an adaptable and flexible basis, be appropriate to the pattern of drug misuse within the catchment area concerned and be able to respond to changes in patterns of drug use and treatment demand.

The Group recommends that service providers put in place procedures to ensure that young people are protected from negative peer influences by older people in a treatment context.

The Group recommends that prevention and early intervention initiatives should focus primarily on developing and supporting protective factors in relation to those most at risk and that the prevention and early intervention initiatives set out in the National Drugs Strategy should be accelerated.

The Group recommends that research in the area of young people and substance misuse be prioritised as part of the research programme of the National Advisory Committee on Drugs and that in that context research in relation to early school leavers, young homeless persons and young parents with substance misuse problems be given particular attention. 


\section{Legal and Ethical Issues}

The Group recommends that services attempt to involve the client's family in the treatment of child and adolescent drug misusers as a first priority.

The Group recommends that young persons between the ages of 16-18 should be considered capable of consenting to drug treatment services on their own behalf where the professional assessment is that the young person is competent to give informed consent on his/her own behalf.

The Group while noting that a very small number of cases arise, in the context of drug prevention and treatment, where the issue of secure residential care may need to be examined, felt that further consideration needs to be given to the issue of the provision of such care.

The Group recommends that substitution treatment for under 18 year olds should not be initiated outside a specialist context.

The Group recommends that needle exchange for under 18 year olds should take place where possible in the context of a broad treatment regime.

\section{Model of Service Delivery}

The Group recommends that services for child and adolescent problem drug misusers should include prevention and treatment and should be based on the Four Tiered Model of Adolescent Addiction Treatment set out in this report.

The Group recommends that the development of Tier 3 services could appropriately evolve in different ways depending upon the pattern of drug misuse within the catchment area.

The Group recommends that the establishment of adolescent specific services within the HSE Eastern Regional Area need to be progressed as a matter of urgency. The key factor in this regard was identified as the establishment of a properly resourced multi-disciplinary team(s) capable of supporting existing services and of developing new services within existing physical structures, for example general adolescent services, health centres etc. 


\section{CONCLUSIONS AND RECOMMENDATIONS}

At the same time, the Group is conscious of the need to address service access outside the HSE Eastern Regional Area, where the smaller numbers of drug misusers raise additional challenges as regards the availability of adolescent specific accessible addiction services. However, the Group is strongly of the view that the tiered model can be adapted to suit circumstances outside of the HSE Eastern Regional Area and recognises the potential for Regional Drugs Task Forces to help create the treatment networks required. With that in mind, the Group recommends that Regional Drugs Task Forces should assess for their areas how best the tiered treatment model could be delivered in their areas as part of their development of strategies for their areas.

\section{Access to Services}

The availability of services appropriate to and capable of attracting and retaining, children and adolescents experiencing substance misuse problems emerged as a key concern of both service users and service providers during the consultation on this issue.

Based on the literature and data available and the concerns raised, the Group recommends that services should:

- strive to be adolescent specific, but didn't need to be addiction specific

- be local and accessible

- have multiple disciplines available on-site

- be able to offer assessment, treatment and aftercare.

Linkages with other services is viewed as a crucial element of access to services, particularly in relation to the necessity to provide children and adolescents with a coherent care pathway throughout the different services with which they may interact, including childcare services, mental health services, criminal justice services etc.. The Group feels that the successful implementation of the tiered treatment model would form a solid basis for providing the necessary networks and links in this context.

\section{Resource Requirements}

It is clear that addressing the needs of under 18 year olds will require additional resources to be directed at this client group. 
In part the resources required should be released through greater co-ordination of the efforts of the wide range of bodies involved in funding and delivering services in this area, e.g. HSE, Local Drugs Task Forces, Partnerships, Probation and Welfare, Gardaí, Prison Services, Department of Education and Science, FÁS, community and voluntary sector treatment providers etc.

Achieving greater co-ordination and maximising the impact of existing resources also requires the support and leadership of Tier 3 services.

In this context Regional Drugs Task Forces can have a very significant role and specific consideration should be given to resourcing this role in the development and implementation of their strategic plans. In particular, the Group felt that funding should be made available to each Regional Drugs Task Force outside the HSE Eastern Regional Area to provide for the appointment of a person to look at the links and gaps in the existing service.

Within the HSE Eastern Regional Area, additional investment needs to be made in relation to the development of Tier 3 services as a matter of urgency.

\section{Review and Monitoring}

The Group is aware of the view that a review mechanism should be agreed within the context of the National Drugs Strategy to monitor the development of services for children and adolescents in relation to substance misuse problems. The review mechanism should involve the regular reporting on progess in respect of the implementation of this report to the Inter Departmental Committee on Drugs and Social Inclusion. 


\section{Appendix I Membership of Working Group}

Ms. Stephanie Bourke, The Drug Treatment Centre Board

Dr. Ciarán Browne, HSE Eastern Regional Area

Fr. Sean Cassin, Merchant's Quay Voluntary Treatment, NDST

Mr. Malcolm Darrach, HSE East Coast Area

Dr. Ide Delargy, National GP Co-Ordinator

Mr. Jim Doyle, HSE South West Area

Mr. Bill Ebbitt, HSE Midland Area

Ms. Vivienne Fay, HSE East Coast Area

Dr. Clare Fitzpatrick, HSE South Western Area

Mr. John Harkin, FÁS

Ms. Sheila Heffernan, The Drug Treatment Centre Board

Dr. Derval Howley, HSE Eastern Regional Area

Ms. Mary Jackson, Department of Health and Children (Member of Group and Chair until May 2002)

Dr. Eamon Keenan, Consultant Psychiatrist, HSE South Western Area

Ms. Valerie Kelly, Crinan Youth Project

Mr. Joe Lucey, Crinan Youth Project

Ms. Celine Martin, Inchicore Community Drug Team

Mr. Fergus McCabe, Community Sector

Mr. Peter McCormack, Provider Forum, Youth Homelessness

Fr. Peter McVerry, Arrupe Society

Mr. David Moloney, Department of Health and Children (Chair) (Replaced Ms. Jackson as Chair in May 2002)

Mr. Seamus Noone, The Drug Treatment Centre Board 
Dr. John O'Connor, Consultant Psychiatrist, The Drug Treatment Centre Board

Ms. Alice O'Flynn, HSE Eastern Regional Area

Ms. Aileen O'Gorman, National Advisory Committee on Drugs

Ms. Mary O'Shea, Merchant's Quay Voluntary Treatment, NDST

Dr. Cathal O' Sullivan, HSE East Coast Area

Ms. Leslie Proudfoot, Alcohol Treatment Unit, Baggot St Hospital

Mr. Julian Pugh, HSE Eastern Regional Area

Ms. Jean Rafter, Provider Forum, Youth Homelessness

Dr. Siobhan Rooney, Consultant Psychiatrist

Mr. Jim Ryan, HSE East Coast Area

Mr. Declan Reddy, HSE East Coast Area

Ms. Isobel Somerville, HSE Northern Area

Dr. Brion Sweeney, Consultant Psychiatrist, The Drug Treatment Centre Board

Dr. Bobby Smyth, Consultant in Adolescence Psychiatry and Substance Misuse, HSE South Western Area 


\section{Appendix II - Mapping of Services within the Eastern Region}

This appendix contains a mapping of services provided by HSE Areas and voluntary/community agencies for under 18 year olds presenting with serious drug problems within the Eastern Region. The mapping is not intended to be exhaustive, as service provision constantly expands and changes in order to meet new challenges and needs. Nonetheless it is hoped that it will give a sense of the range of services which are available.

\section{Services available to Under 18 year olds in HSE East Coast Area}

\section{HSE ECA Treatment Centres and Satellite Clinics}

Following rigorous assessment and with appropriate consent, detoxification programmes are provided to a small number of persons under 18 years in the following Addiction Centres and Satellite Clinics:-

\section{Patrick Street Clinic, Baggot Street Clinic, Dundrum Clinic, Sallynoggin Health Centre, Mounttown Oasis Project, Strand Road Health Centre, Fassaroe Ard Chulann, Ballywaltrim/Lincara Centre, Loughlinstown Centre.}

Service provision in the addiction centres and satellite clinics is based on a multi-disciplinary approach in the care and treatment of clients. When receiving treatment, clients have access to the clinical team, which includes a Psychiatrist, General Practitioner, Nurse, Pharmacist and Counsellor, which is augmented by other members of the multi-disciplinary team including Outreach Workers, General Assistants and Administration staff. Onsite dispensing of medication is provided.

In the event that a client who is under 18 years old presents for assessment, they are prioritised for treatment. Treatment initiated is individualised and based on a comprehensive assessment of their drug use. The nurse carries out the initial assessment and the General Practitioner assesses the client for treatment. Currently a counselling service is available to clients under 18 years old whether or not they are attending treatment services. Referrals are accepted from GP's, Outreach Workers, Counsellors, other agencies or by self-referral. 


\section{Addictions Centres}

Patrick Street Clinic: Contact Michelle Keavney, Nurse, 99 Patrick Street, Dun Laoghaire, Co Dublin. Monday - Friday, 9am-5pm. Phone:01-2808472/2808482.

Baggot Street Clinic: Contact Linda Natham, Nurse, 19 Haddington Road, Dublin 4, Monday- Friday between 9am-5pm. Phone: 01-6699500 Freephone:1800 201187.

\section{Satellite Clinics:}

Dundrum Clinic: Contact Lori O'Brien, Upper Churchtown Rd, Dublin 14. Phone: 01-2983116/3200.

Sallynoggin Health Centre: Contact Michelle Keavey, Nurse, Health Centre, Upper Glenageary Road, Sallynoggin, Co Dublin. Phone: 01-2800786/2806754.

Mounttown Oasis Project: Contact: Lori O'Brien, Nurse, c/o Patrick Street Clinic, 99 Patrick Street, Dun Laoghaire, Co Dublin. Phone: 01-2802472/2802482.

Strand Road Health Centre: Contact Michelle Keavney, Nurse, Strand Road, Bray, Co Wicklow. Phone: 01-2862008.

Fassaroe Ard Chulann: Contact: Mairead Fahy, Nurse, c/o Little Bray Family Resource Centre, Fassaroe, Bray, Co Wicklow. Phone: 01-2867644.

Ballywaltrim/Lincara: Contact: Mairead Fahy, Nurse, c/o Lincara Centre, Boghall Road, Bray, Co Wicklow. Clinics operate Monday from 5.30 to $7.30 \mathrm{pm}$ and Tuesday to Thursday from 7.30 to $9.30 \mathrm{pm}$.

Loughlinstown: Contact: Nora Grennan, St. Colmcille's Hospital, Loughlinstown, Co Dublin. Phone: 01-2115169. Clinics operate Tuesday to Thursday between $11 \mathrm{am}-1 \mathrm{pm}$.

\section{HSE ECA Needle Exchange Services}

Needle Exchange Services are provided under strict guidelines for under 18 year olds.

Arklow: Back Packing Needle Exchange facilitates harm reduction and provides referral of clients to services where possible, by engaging with clients in their 
homes. Referral is by word of mouth and access to services is via John Craven, Outreach Worker. Phone: 086-8590734.

Sallynoggin: Facilitates harm reduction and referral of clients to services where possible. Services can be accessed by presenting at Sallynoggin Health Centre, Upper Glenageary Road, Co. Dublin, Monday and Thursday between 6.30 - 7.30pm. Contact: Melvin Bay. Phone: 01-2808472.

Strand Road: Facilitates harm reduction and referral of clients to services where possible. Services can be accessed by presenting at Strand Road Health Centre, Tuesday between 6-7pm. Contact: Michael Gormley. Phone: 01-2862008.

\section{HSE ECA Prevention and Health Promotion}

Ranelagh/Rathmines Drug Awareness Project: This project raises the level of drug awareness in schools, non-formal education sector and communities together with the provision of information and support. The project is partially funded by the HSE East Coast Area through section 65 grants and partially funded by St. Vincent de Paul. Referral to the project is from a variety of sources. Contact: Celine Dillon, Education Co-ordinator, 5 Dartmouth Place, The Mews, Dublin 6. Phone: 01-4960860.

EURAD: Compiles and distributes educational materials on drug misuse through a variety of sources including a resource and research library and website. It also provides personal counselling and family intervention for teenagers and their families and refers clients onto appropriate agencies (e.g. The Drug Treatment Centre Board, Rutland Centre). Contact: Fr. Padraig O'Fithchill, Administrator, 8 Waltersland Road, Stillorgan, Co Dublin. Phone: 01-2756766.

\section{HSE ECA Prevention and Health Promotion / Treatment}

The Women's Health Project: Promotes the health and well-being of women involved in prostitution. Clients attending the project have access to medical and addiction services, including on site STI screening, specialist advice and health promotion, outreach services and community welfare. A drop-in service is in operation Wednesday $2-4 \mathrm{pm}$ and Thursday 8.30-10.30pm. Contact: Jo Gore, 19 Haddington Rd, Baggot Street, Dublin 4. Phone: 01-6699515 Freephone: 1800201187. 


\section{Detoxification}

Cuan Dara: Provides in-patient facilities for detoxification and stabilization. There is no designated programme for under 18 year old clients. However, treatment for this age group is regarded as a priority. Access to Cuan Dara is through Counsellor referral to The Drug Treatment Centre Board for pre-assessment and several meetings with a Counsellor in Cuan Dara before the client is admitted. Contact: Maria White, Cuan Dara, Cherry Orchard Hospital, Dublin 10. Phone: 01-6235811.

Beaumount Hospital: Provides in-patient facilities for detoxification and stabilization. However, there are no designated beds allocated for clients under 18 years old. A weekly meeting to review clients for treatment in St. Michael's Ward/The Drug Treatment Centre Board takes place in the Drug Treatment Centre. Clients under 18 years old presenting to the Drug Treatment Centre are assessed as a priority on the same day and every effort is made to provide treatment within a week. The decision of the Drug Treatment Centre to refer a client to St. Michael's as an in-patient is determined by the circumstances of each individual case. Contact: Margaret Casserly, Ward Manager, St. Michael's Ward, Beaumount Hospital. Phone: 01-8093288. Seamus Noone, Clinical Operations Manager, The Drug Treatment Centre Board. Phone: 01-6488600.

St. John of Gods: Is a private hospital providing detoxification, group work and counselling. Contact: Administration, St. John of Gods, Stillorgan, Co Dublin. Phone: 01-2771400.

Shankill Counselling Service: Provides professional counselling to clients. Referral is from clients themselves, Public Health Nurses, GPs, Outreach Workers, St. John of Gods or Task Forces. Contact: Jenny Sloney, Service Co-ordinator, 2-3 Quinns Road, Shankill, Co Dublin. Phone: 01-2820110/2720793.

Community Addiction Team Arklow: Encourages and entices clients into care by assessment and care planning and links them with appropriate treatment services, while providing support to significant others. Referrals are accepted from GPs, Counsellors, schools or by self referral. Funded by the HSE ECA. Contact: John Mulhare, Co-ordinator. Phone: $040233577 / 33693$.

\section{Aftercare}

Keltoi: Provides a residential rehabilitation programme commencing with the development of a therapeutic alliance with the resident. Therapeutic work is cognitive behavioural and occurs throughout all aspects of living in Keltoi. Issues that may impede 
recovery are also addressed. The client is prepared for independence and support is sought from aftercare and rehabilitation. HSE Services facilitate this process as part of the clients care plan. The eight-week programme focuses strongly on occupational work and every effort is made to ensure that the programme is client centred to enable clients to develop strategies to assist them to cope on their discharge.

Referrals are taken from a number of agencies. Clients must be drug-free with the exception of Psychotropic medication prior to being admitted and admission is voluntary. Arrangements can be made for direct transfer to Keltoi from a residential detoxification unit. If detoxification has been on an out-patient basis, a client must be drug-free for 2-6 weeks. Contact: Annie Tudor, Manager, Keltoi. Phone: 01-6200040.

Aislinn Adolescent Treatment Centre: Caters for adolescents with chemical dependency problems. Referrals are accepted from HSE, Gardaí and probation services. Screening appointments for clients are arranged and referral for admission then decided upon. Clients must be drug-free prior to admission. Contact: Breda Cahill, Administrator, Address: Ballyragget, Co Kilkenny. Phone: 056-8833777.

\section{Dun Laoghaire/Rathdown Local Drug Task Force}

PMCA: Promotes school based drug education. Funding for PMCA is provided through Dun Laoghaire/Rathdown Local Drug Task Force. Referral is through direct contact with schools. Contact: Lucy Lourlander, 63 Ardragh Park, Blackrock, Co Dublin. Phone: 01-2756899.

Ballyogan Early School Leavers: Assists young people access training and secure employment. Funding is provided through Dun Laoghaire/Rathdown Local Drug Task Force. Contact: Ann Doherty, C/o Ballyogan Resource Centre, Ballyogan, Co Dublin. Phone: 01-2953219.

Dun Laoghaire Prevention through play: Investigates programmes for younger groups. Funding is provided through Dun Laoghaire/Rathdown Local Drug Task Force.

Counselling for Young People on Juvenile Liaison Scheme: Gives younger people access to suitable and timely counselling as not to re-offend. Funding is provided through Dun Laoghaire/Rathdowne Local Drug Task Force. Contact: Inspector Pat Ward, Dun Laoghaire Garda Station, Carraig Road. Phone: 01-6665000. 
Queen of Angels School: Provides school based Prevention/Education Programmes. Funding is provided through Dun Laoghaire/Rathdown Local Drug Task Force. Contact: Ian Alderdise, Queen of Angels School, Monkstown Farm, Dun Laoghaire, Co Dublin.

Alternative High Project: Is aimed at 10-18 year olds not attracted to the more formal youth club structure. Funding is provided through Dun Laoghaire/Rathdown Local Drug Task Force. Contact: Peter O'Brien, Dun Laoghaire Youth Services, Bell Tower, Marine Rd, Dun Laoghaire, Co Dublin.

Bray Local Drug Task Force/Living Life Centre: Provides family and individual support and counselling. Services can be accessed through self referral and referral from other agencies. Funding is provided through private sources and Bray Local Drug Task Force. Contact: Heather Browne. Phone: 01-2866729.

Bray Youth Services: Provides Drug Education in schools in the Bray area for children under 12 years old. The programmes are adapted to suit the age of children and are run over a seven-week period with one session a week per group. Funding is provided by the Bray Local Drug Task Force. Contact: Rosemary Yeates. Phone: 01-2828325.

Youthreach: Provides education for early school leavers. The services can be accessed through voluntary, statutory or community agencies. Funding is provided by the V.E.C. Contact: Paddy Robinson. Phone: 01-2869598.

Bray Community Addiction Team: The objective of this project is to develop services for drug users and families of drug users, community based drug education and preventative initiatives, and the provision of drug free rehabilitation. Contact: Vivienne O'Brien, Community Addiction Team, Boghall Road, Bray. Phone: 01-2764692.

\section{Services available to Under 18 year olds in HSE South Western Area}

Structured Interventions for under 18 year olds in the HSE South Western Area are predominately provided through:

- The Young Persons Programme at Fortune House Treatment Centre

- The Drug Treatment Centre Board - Young Adults in Action

- Cuan Dara, Detoxification unit, Cherry Orchard

- Helpline, AIDS/Drugs

- Addiction Centres and The Drug Treatment Centre Board under specific arrangements

- Voluntary organisations and Section 65 organisations. 


\section{Fortune House}

Fortune House opened in 1997 and it quickly became apparent that there was a need for a specific and dedicated service for young people. Services are provided by a multi-disciplinary team including Psychiatry, General Practice, Pharmacy, Nursing, Counselling and Family Therapy. The programme has a strong emphasis on personal development and development of life skills. The programme also actively involves families as an integral part of the Young Persons Programme. Strong emphasis is placed on individual, group and family therapy. Weekly multi-disciplinary meetings occur to review progress and to define goals. Aftercare support is available for those who successfully complete the programme.

Contact: Aoife Fitzgerald, Nurse. Tel: 01-6206030.

\section{The Drug Treatment Centre Board Young Persons Programme}

The Drug Treatment Centre Board is an independent statutory organisation, the longest and largest established treatment service in the country. A range of specialist services are provided which includes a dedicated programme for 18 year olds and under. This innovative programme is designed to meet the complex needs of young drug users (18 years and under), many of whom are homeless. The programme adopts a holistic approach that addresses the physical, psychological, emotional and social needs of the young person and their family. The programme is supported by a dedicated, highly skilled and experienced multidisciplinary team, who work in collaboration with external agencies through joint care planning and interagency work.

In addition, The Drug Treatment Centre Board acts as a tertiary service to support agencies working in the area of substance misuse.

Contact: Seamus Noone. Tel: 01-6488677.

\section{Cuan Dara, Detoxification Unit, Cherry Orchard.}

This unit opened in 1995 to provide detoxification for opiate users from the HSE Eastern Region and stabilisation for pregnant opiate addicts. The programme lasts for 6 weeks, the first two to three weeks on reducing medication and the remainder drug free. Clients are involved in Counselling, Group Therapy and family involvement where appropriate.

This service has experienced an increase in the number of underage drug users requiring admission. Whilst the programme is provided alongside services for adults, significant emphasis is placed on developing specific methodologies for 
dealing with adolescents and their specific needs and fast tracking young people where necessary.

This specific approach to the adolescents has resulted in staff becoming more aware of the dynamics and needs of the group and increased retention rates for adolescents.

Contact: Clinical Nurse Manager. Tel: 01-6206050.

\section{Helpline}

The AIDS/Drugs Helpline is operated by the HSE South Western Area and is available on a seven-day basis to offer a confidential service including support, guidance and information on drug and HIV related issues.

Contact: Tel: 01-6206083. Freephone 1800459459.

\section{Addiction Centres}

Following rigorous assessment and where there is appropriate consent, detoxification programmes are provided to a small number of persons under 18 years old. Whilst there has always been reluctance about placing adolescents on a maintenance programme, some adolescents may have had a particularly long history of heroin addiction. Insistence on detoxification or discontinuation of treatment often results in a return to illicit use. In some cases a preferred option may be to retain the individual in treatment by the provision of a Methadone Maintenance Programme. This is only considered after detailed discussion with the multidisciplinary clinical team at the centre. Parental consent must be sought where appropriate.

\section{Addiction Centres:-}

37 Castle Street, Dublin 2. Tel: 01-4767010

Cork Street Clinic, Cork Street, Dublin 8. Tel: 01-4544933

Dr. Steevens' Clinic, Dublin 8. Tel: 01-6352078

Fortune House, Cherry Orchard Hospital, Dublin 10. Tel: 01-6206030

Aisling Clinic, Cherry Orchard Hospital, Dublin 10. Tel: 01-6206010 


\section{APPENDICES}

Millbrook Lawns Health Centre, Tallaght, Dublin 24. Tel: 01-4520666

Old County Road Health Centre, Crumlin, Dublin 12. Tel: 01-4154807

Curlew Road Treatment Centre, Drimnagh, Dublin 8. Tel: 01-4556422

Inchicore Health Centre, Unit 13, Goldenbridge Industrial Estate, Dublin 8.

Tel: 01-4531978

Irishtown Health Centre, 1A Irishtown Rd, Dublin 4. Tel: 01-6608629

Jobstown Community Centre, Tallaght, Dublin 24. Tel: 01-4597756.

\section{Community Drug Teams}

Under a joint initiative with Ballyfermot and Clondalkin Task Forces and the HSE Eastern Region, two specific teams were set up on the Clondalkin and Ballyfermot area, comprising Social Workers and Child Care Workers. The function of these teams is to deal with families where both substance misuse and childcare issues are present. The team's primary function would be more towards the area of childcare issues in families but they would also deal with social work issues related to young persons under 18 years old. Again their primary target would be much younger children who were not substance misusers.

Contact: Mr. David Kennedy. Tel: 01-6206441.

\section{Mater Dei Counselling Centre}

Mater Dei Counselling Centre initiated Teen Counselling, Tallaght and Teen Counselling, Quarryvale, Clondalkin to provide community based counselling services for adolescents and their families who live in the Tallaght and Clondalkin area. Substance misuse would be a predominant issue in a significant number of cases who present to this service for counselling. By addressing these problems within the context of the family the service aims to maintain adolescents within their homes and schools and also to contribute to the prevention of drug misuse. The teams comprise a Principal Psychologist, Senior Psychologist, Psychologist, Senior Social Workers and Social Workers. A Psychiatrist is available on a consultancy basis as required.

Contact: Teen Counselling, Quarryvale, Clondalkin. Tel: 01-6231398

Teen Counselling, Tallaght, Dublin 24. Tel: 01-4623083. 


\section{Focus Ireland}

Focus Ireland Outreach is a seven-day specialised street based outreach service that works alongside and supports people who are out of home and sleeping rough in the city of Dublin. The target group for the Outreach Team is young people under the age of twenty-five years. Focus Ireland have two dedicated outreach workers for young people. The Outreach team offer a drop-in service for three hours in the morning, $11.00 \mathrm{am}$ to $2.00 \mathrm{pm}$ and one hour in the evening, $6.00 \mathrm{pm}$ to $7.00 \mathrm{pm}$. Outside of these hours the Outreach Workers work mainly on the streets in the Dublin city centre area. Much of the work of the Outreach team involves referring to specific programmes and providing informal support and information in regard to homelessness and drug issues.

Contact: Focus Ireland. Tel: 01-6770691.

\section{Community Awareness on Drugs (CAD)}

Community Awereness on Drugs provides residential training weekends, drug education days and parenting programmes. These are generally for persons over 18 years old. However, they also provide an advisory and referrals source to persons of all ages. This service is available Monday to Friday during office hours. They also provide an information service to students and the general population who wish to learn more about drug related issues.

Contact: Tel: 01-6792681.

\section{CARP, Killinarden}

CARP Project does not provide direct treatment services for under 18 years old. However, it does provide support services for under 18 years old who are experimenting with heroin. The CARP Project runs a drop-in centre twice a week which provides group and one to one services for teenagers at risk of serious drug use. CARP also work with the children of drug users in collaboration with Barnardos and the local primary school.

Contact: Tel: 01-4626033 /01-4626082.

\section{CUMAS Project}

The CUMAS Project provides support for young people and families in the Clondalkin area affected by drug misuse through individual and group programmes. It currently provides siblings groups, drop-in services and peer education.

Contact: Tel: 01-4573515.

\section{Inchicore Community Drug Team/St Michaels Youth Project}

The Inchicore Drug Team promotes awareness in young teenagers, both male and 
female between the ages of 14 and 16, about issues relating to drug use and sexual activity. It seeks to encourage active participation in developing their knowledge of these issues through discussion, outreach, drop-in and health promotion. It currently employs one community drugs worker who specifically targets young people in conjunction with the St Michael's Parish Youth Project.

Contact: Tel: 01-4736502.

\section{The Rialto Youth Project}

The Rialto Youth Project provides individual and group support, outreach and family support to young persons in the Rialto area. It employs a Youth Worker to work with 14 to 21 year olds and works closely with the Rialto Community Drug Team. Contact: Jim Lawlor. Tel: 01-4531638.

\section{The Lorien Project}

The Lorien Project works with young parents in the Dublin 24 area providing support, parenting programmes and home visiting, as well as providing information on drug issues. Some of its clients are under 18 years old.

Contact: Tel: 01-4525090.

\section{Services available to Under 18 year olds in the HSE Northern Area}

\section{City Clinic / Thompson Centre}

Services are provided by a multi-disciplinary team including Psychiatry, General Practice, Pharmacy, Nursing, Counselling, General Assistants and Administration. Outreach Workers Services are provided through Needle Exchange and street work. Needle Exchange is not implemented without parental consent or assessment by Consultant Psychiatrist.

Under 18 year olds are referred to Crinan Project if they're unsuitable / not willing to access treatment in City Clinic. It does, however, have a comprehensive treatment plan and has treated under 18 year olds since the programme started 4 years ago.

Contact: Dr. Des Crowley, GP Co-ordinator. Tel: 01-8555310, Fax: 01-8555314, Thompson Centre: Tel: 01-8602000 / Fax: 01-860 3417. 


\section{Cuan Dara, Cherry Orchard Hospital, Ballyfermot, Dublin 10}

This service provides treatment for persons of all ages with under 18 year olds being given priority. However due to demand on service only two/three can be admitted to the programme at any one time.

Contact: Maria White. Tel: 01-6235811, Fax: 01-6235835.

\section{Soilse}

This service generally provides treatment for over 18 year olds. However, under 18 year olds will be assessed for treatment on an individual basis.

Contact: 6/7 North Frederick Street, Dublin 1. Tel: 01-872 4535, Fax: 01-872 4586

or 1/2 Henrietta Place, Dublin 1. Tel: 01-872 4922, Fax: 01-872 4891.

\section{Education Service Provision for under 18 year olds}

The Education Service provides comprehensive prevention/education initiatives which promote healthy choices regarding substance use, misuse and Hepatitis. With reference to under 18 year olds, it is accepted good practice that school-based prevention and education is most effective when it is on-going, developmental and integrated into Social, Personal and Health Education (S.P.H.E.) and when it is supported by school policy. The Education Service's Strategy reflects this approach through the following actions:

- Establishing contact with every primary school and secondary school in the HSE Northern Area in order to support the adoption of the Department of Education and Science S.P.H.E. programmes, through co-operation with the HSE Northern Area Schools Health Promotion Officer and the Department of Education and Science regional development officer for S.P.H.E.

- Providing training and on-going support for the development of Schools Substance Use Policy

- Supporting the training of teachers in conjunction with the Department of Education and Science and the Schools Health Promotion Officer

- Promoting the role of parents by ensuring the centrality of their role in all facets within the school setting

- The above actions are on-going and impact directly on every school going child at primary and post-primary level

- In terms of the Informal Youth Services Sector the Education Service actively participates in the development of appropriate interventions for specific target groups such as Youth Clubs, After-School Initiatives, Early School Leavers Projects and Diversionary Projects in conjunction with other Statutory and Voluntary Agencies and Community Groups.

Contact: Tel: 01-882 0300, Fax: 01-882 0330. 


\section{Mater Dei Counselling Centre, Clonliffe Road, Dublin 3}

Mater Dei Counselling Centre was established in 1973 to service school going people from 12 - 18 years and their parents and to address general adolescent problems. The catchment area was established in Areas 6, 7 and 8 of the HSE Eastern Region. With the increase in drug use in the early ' 80 s, drug prevention and early intervention became an important part of the work and where there was a concern, young people from anywhere in the HSE Eastern Region area were accepted.

The HSE Eastern Region, the Department of Social, Community and Family Affairs and Crosscare are the main funders of the service.

Contact: Tel: 01-837 1892, Fax: 01-837 2025.

\section{Ballymun Youth Action Project (YAP)}

Ballymun Youth Action Project was established in 1981 as a community response to drug abuse in the area. The aims of the Ballymun Youth Action Project are:

- To develop a community response to drug misuse.

- To provide advice, information and support to those who are addicted and to those living with addiction

- To develop preventative services, particularly in relation to young people at risk or vulnerable to drug abuse

- To engage in community education in drug abuse

- To work closely with other voluntary and statutory groups providing community services

- To facilitate research into drug abuse in the area.

A Counselling and support service for drug users and their families is available to males / females who are either living with addiction or using drugs / alcohol. Contact can be either formal or informal, street, residential centre based, home or institutional.

They run an under 16 year olds Drop-In Centre which aims to:

- Raise self-esteem

- Challenge peer pressure

- Raise awareness of local resources

- Explore options and choices

- Provide other support

- Strengthen social networks / links. 
The Day Programme is aimed at helping drug users (age 17 upwards) achieve increased stability and make positive changes in their lives. These aims are realised through a programme of educational, social and health orientated activities and modules by building up levels of numeracy and literacy skills.

Contact: 1A Balcurris Road, Ballymun, Dublin 11. Tel: 01-842 8071, Fax: 01-862 1025.

\section{DAP (Drug Awareness Programme)}

\section{Programme Objectives:}

To organise a diocesan response to drug / substance related problems especially:

- Prevention through training programmes for youth and adults

- Treatment through counselling and referral

- In the case of under 18 year olds, where referral is made though parent or guardian.

\section{Courses Run by DAP:}

- Primary School Project - 9 week programme for students, teachers and parents, using focus groups and drama to develop skills and knowledge to avoid drug problems

- Post-Primary School Project (similar to Primary School Project)

- Short courses on drug awareness and personal development to under 18 groups

- Individual therapy (counselling) is offered to all age groups.

Contact: Tel: 01-8360911, Fax: 01-8360745.

\section{Crinan Youth Project}

Crinan Youth Project provides medical, therapeutic and social/educational support to 15 - 21 year olds, who have problems with drugs. They follow a detoxification approach to the medical part of treatment, gradually reducing levels of methadone and not prescripting for more than $50 \mathrm{mls}$. Their preference is not to prescribe methadone to participants who are under 16 years.

Referrals come from City Clinic, HSE Northern Area services, Community care, Probation services, local community, local families and self-referral.

Crinan's programme contains the following components:

- Therapy (Individual and Family Therapy)

- Alternative Therapies (auricular acupuncture, yoga, herbal therapies, massage etc.)

- Medical (G.P. supervision, urinalysis etc.) 
- Health Education

- Social Education

- Recreation, Creativity and Fitness Education

- Career Education

- Community Development.

Contact: 72 Sean McDermott St, Dublin 1. Tel: 01-8558792, Fax: 01-8552320.

email: cproject@gofree.indigo.ie

\section{Talbot Centre}

The Talbot Centre provides education and prevention programmes. It provides support and a befriending counselling service for children, young people and families at risk and / or using drugs. It runs the following programmes for under 18 year olds:

- One to one work - support, advocacy, information and counselling

- Child and family work - flexible, broad range of family support with parents and children

- Health Promotion Workshops - HIV, Hepatitis B, Safer Sex, Education and Outreach

- Prison Units - engaging with those at risk, making links prior to release one-to-one prisoner client work on a weekly basis.

Referrals can be made by phoning, writing or calling to the door. Funding for the Talbot Centre is provided through the HSE Northern Area.

Contact: 29 Upr. Buckingham Street, Dublin 1, Tel: 01-836 3434, 01-855 3910.

\section{Blakestown and Mountview Youth Initiative}

It supports young people "at risk" and their families, in the Blakestown and Mountview areas of Blanchardstown.

Funding is provided through:

- Drugs / AIDS Service, HSE Northern Area

- Fingal County Council

- Leargas

- Br. Edmund Rice Trust

- VEC

- Young Peoples Facilities and Services Fund

- OSCFA 
Referrals from NYP, CDTs, Blakestown Community School, Social Work Team, VEC, Youth Services, Barnardo's.

They provide the following services to under 18 year olds:

- Young Men's Group - gender specific developmental work

- Young Women's Group - gender specific developmental work

- Arts and Crafts - NCVA Level 1

- Junior Certificate - evening and developmental work

- Peer training

- Sports group - NCVE Sport and Development Work

- Computer training

- One-to-one work with children.

Contact: Unit 4, Blakestown Shopping Centre, Blakestown Way, Dublin 15, Tel: 01-821 0055, Fax: 01-821 0677.

\section{Blakestown and Mountview Neighbourhood Youth Project (NYP)}

The objectives of this project are follows:

- To empower the community to respond to youth needs, thus enabling families to take greater control of their lives

- To facilitate the social and personal development of the young people on the project

- To empower young people to realise their educational potential

- To support parents and guardians.

It runs the following programmes:

- Parent Support Groups - some education and prevention work is carried out with the Parents Group as appropriate and in response to particular needs

- Life skills as an on-going programme.

Funding is provided through:

- HSE Northern Area - project core funding

- Community Development and Family Support Programme

- NDST through HSE Northern Area.

Referrals are received from local schools, special schools and Social Workers. Clients are prioritised taking account of the level and nature of risks, family circumstances and stability. Contact: Shelerin Road, Clonsilla, Dublin 15. Tel: 01-820 5253, Fax: 01-820 6356. 


\section{Hartstown / Huntstown Community Drug Team:}

Hartstown/Huntstown Community Drug Team run the following programmes:

- Primary School Drug Awareness - a 10 week programme that deals with information regarding drugs and alcohol

- Drug Information Workshops

- Drug Information Week - various agencies giving talks in schools

- Peer Support Group.

They are funded by the HSE Northern Area. They take referrals from anyone and provide an open door policy for people calling to the CDT. Contact: Unit D, Coolmine Industrial Estate, Dublin 15. Tel: 01-8211385, Fax: 01-8213636.

\section{Mulhuddart / Corduff Community Drug Team}

Mulhuddart/Corduff Community Drug Team is funded by HSE Northern Area (Section 65 grants). Referral pathways include self referral, referral by statutory, voluntary, community agencies and groups, i.e. Probation and Welfare, JLO, colleges, family and friends. Also through their Project Workers at Satellite Clinics and Needle Exchange. The aims of the Drug Team are as follows:

- To develop systems of working with substance misusers in / and not in treatment in Corduff and Mulhuddart

- To develop systems of working with families of drug users

- To liaise / work with local schools and colleges

- To develop training courses / workshops.

Open $9.00 \mathrm{am}$ - $5.00 \mathrm{pm}$ Monday - Friday and does street work Wednesday and Thursday evenings 6.00 pm - 8.00 pm each week.Contact: Parslickstown House, Parslickstown, Mulhuddart, Dublin 15. Tel: 01-821 6601, Fax: 01-821 6177.

\section{Ana Liffey Drug Project}

This is a programme of support to drug users and their families. It is funded through: HSE Northern Area - AIDS/Drugs Service (Section 65) and Children and Families and the North Inner City Drugs Task Force.

There are a number of options for referral: self-referral or referral from a number of voluntary and statutory agencies. Ana Liffey runs the following programmes for under 18 year olds:

- Links with drug users through Outreach 
- Children's Project - to support families and children affected by drug use

- Offer support and education.

In terms of under 18 year olds using drugs, Ana Liffey refers them to the Crinan Project or Focus Ireland. Ana Liffey targets under 18 year olds with the aim of moving the young people on to a service which caters for their needs.

112 Middle Abbey Street, Dublin 1, Tel: 01-878 6899, Fax: 01-878 6828. 